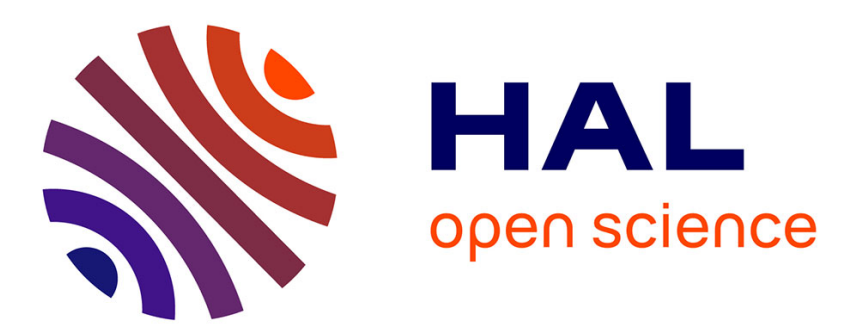

\title{
A family of sinus finite elements for the analysis of rectangular laminated beams \\ P. Vidal, O. Polit
}

\section{To cite this version:}

P. Vidal, O. Polit. A family of sinus finite elements for the analysis of rectangular laminated beams. Composite Structures, 2008, 84 (1), pp.56-72. 10.1016/j.compstruct.2007.06.009 . hal-01366937

\section{HAL Id: hal-01366937 \\ https://hal.science/hal-01366937}

Submitted on 5 Jan 2018

HAL is a multi-disciplinary open access archive for the deposit and dissemination of scientific research documents, whether they are published or not. The documents may come from teaching and research institutions in France or abroad, or from public or private research centers.
L'archive ouverte pluridisciplinaire HAL, est destinée au dépôt et à la diffusion de documents scientifiques de niveau recherche, publiés ou non, émanant des établissements d'enseignement et de recherche français ou étrangers, des laboratoires publics ou privés. 


\title{
A family of sinus finite elements for the analysis of rectangular laminated beams
}

\author{
P. Vidal, O. Polit * \\ LMpX, Université Paris X-Nanterre, 50 rue de Sèvres, 92410 Ville d'Avray, France
}

Available online 12 July 2007

\begin{abstract}
In the framework of a sinus models family, a new three-noded mechanical beam finite element is designed for the analysis of laminated beams. It is based on a sinus distribution with layer refinement. The transverse shear strain is obtained by using a cosine function avoiding the use of shear correction factors. This kinematic accounts for the interlaminar continuity conditions on the interfaces between the layers, and the boundary conditions on the upper and lower surfaces of the beam. A conforming FE approach is carried out using Lagrange and Hermite interpolations. It is important to notice that the number of unknowns is independent from the number of layers.

Both static and vibration mechanical tests for thin and thick beams are presented in order to evaluate the capability of this new finite element to give accurate results with respect to elasticity or finite element reference solutions. Both convergence velocity and accuracy are discussed and this new finite element yields very satisfactory results at a low computational cost. In particular, the transverse stress computed from constitutive relation is well estimated with regards to classical equivalent single layer models. Moreover, this family of sinus model is very efficient owing to the low number of unknowns.
\end{abstract}

Keywords: Multilayered beam; Finite element; Higher order transverse shear; Layer refinement; Legendre polynomials

\section{Introduction}

Composite and sandwich structures are widely used in the industrial field due to their excellent mechanical properties. In this context, they can be submitted to severe conditions. For composite design, accurate knowledge of deflection and stresses is required to take into account effects of transverse shear deformation due to the low ratio of transverse shear modulus to axial modulus, or failure due to delamination, ... In fact, they can play an important role on the behaviour of structures in services, which leads to evaluate precisely their influence on stresses, particularly on the interface of layers.

The aim of this paper is to construct a finite element to analyze laminated beams in elasticity in relation to small displacements, so as to obtain the accurate predictions

\footnotetext{
${ }^{*}$ Corresponding author. Fax: +331470952 24.

E-mail address: olivier.polit@u-paris10.fr (O. Polit).
}

for the distributions of simply supported laminated composite beams subjected to transverse loading.

According to published research, various theories in mechanics for composite or sandwich structures have been developed. They can be classified as:

- the Equivalent Single Layer (ESL): the number of unknowns is independent from the number of layers, but the shear stress continuity on the interfaces of layers are often violated. We can distinguish the classical laminate theory [1] (it is based on the Euler-Bernoulli hypothesis and leads to inaccurate results for composites and moderately thick beams, because the transverse shear is neglected), the first order shear deformation theory, and higher order theories: [2-10] which analyse stresses for beams and plates.

- the Discrete Layer theory or layer-wise approach (DLT): this theory aims at overcoming the restriction of the ESL about the discontinuity of in-plane displacement on the interface layers [11-14] (FSDT), [15]. 
In this framework, some authors have developed the zigzag model in order to improve the accuracy of results and reduce the number of unknowns for multilayered composites. This model has the advantage of taking into account the first derivative discontinuity of the in-plane displacement in the transverse direction. This was first employed by Murakami [16] with Reissner's new mixed variational principle to develop a plate theory. Then, it was also used and improved by Reddy [17], Icardi [18], Di Sciuva [19], Averill [20], Cho [21], Carrera [22], with different order kinematics assumptions. For a review of zig-zag method, see Carrera [23].

A multitude of analysis models for layered structures and corresponding finite element formulations have been developed over many years. An extensive assessment of different approaches has been made by Noor [24], Reddy [25] and Carrera [26].

Thus, a family of finite elements for rectangular laminated beam analysis is built, in order to have a low cost tool, efficient and simple to use. In fact, our approach is associated with the ESL theory. This element is totally free of shear locking and is based on a refined shear deformation theory [27] avoiding the use of shear correction factors for laminates. Our three elements are based on the sinus model [28]. They are $\mathrm{C}^{0}$-continuous except for the transverse displacement associated with bending which is $\mathrm{C}^{1}$. It should be noted that all the interface and boundary conditions are exactly satisfied for displacements and stresses for two of these models. Therefore, this approach takes into account physical meaning. The sinus model is considered in the first place. But the conditions of continuity are not imposed. Then, the second element uses a Heaviside function to satisfy these requirements. It has only the three usual independent generalized displacements: two displacements and one rotation. Finally, the third one is based on the double superposition hypothesis from [29]. Three local functions are added to the sinus model. It yields to only four independent generalized displacements, i.e. only one more than the two previous models.

In this article, first the mechanical formulation for the different models is described. For each of these approaches, the associated finite element is given. They are illustrated by numerical tests which have been performed upon various laminated beams. A parametric study is given to show the effects of different parameters such as length-to-thickness ratio and number of degrees of freedom. The accuracy of computations are also evaluated by comparisons with an exact three-dimensional theory for laminates in bending $[15,30]$ and also twodimensional finite element computations using commercial codes. We put the emphasis on the direct calculation of the transverse shear stress by the constitutive relations. The results of the present model can be compared with the approach consisting in calculating transverse shear stresses from the equilibrium equations as it is necessary in [31-33,9,6,34]. In this framework, other approaches are proposed to evaluate shear stresses accurately. Some authors use a hybrid mixed finite element formulation (cf. [35]). Finally, other numerical examples are presented to demonstrate the effectiveness of the finite element models in dynamic analysis. Computations for thick and thin beams of laminated composites and sandwich structures are compared to exact 2D elasticity solutions and 2D finite element computations.

\section{Resolution of the mechanical problem}

\subsection{The governing equations for mechanics}

Let us consider a beam occupying the domain $\mathscr{B}=[0, L] \times\left[-\frac{h}{2} \leqslant z \leqslant \frac{h}{2}\right] \times\left[-\frac{b}{2} \leqslant x_{2} \leqslant \frac{b}{2}\right]$ in a cartesian coordinate $\left(x_{1}, x_{2}, z\right)$. The beam has a rectangular uniform cross section of height $h$, width $b$ and is assumed to be straight. The beam is made of NC layers of different linearly elastic materials. Each layer may be assumed to be transversely isotropic in the beam axes. The $x_{1}$ axis is taken along the central line of the beam whereas $x_{2}$ and $z$ are the two axes of symmetry of the cross section intersecting at the centroid, see Fig. 1. As shown in this figure, the $x_{2}$ axis is along the width of the beam. This work is based upon a displacement approach for geometrically linear elastic beams. The list of principal notation is given in Table 1 .

\subsubsection{Constitutive relation}

Using matrix notations, the one dimensional constitutive equations of an orthotropic material are given by

$\left[\begin{array}{c}\sigma_{11} \\ \sigma_{13}\end{array}\right]=\left[\begin{array}{cc}\bar{C}_{11} & 0 \\ 0 & \bar{C}_{55}\end{array}\right]\left[\begin{array}{l}\varepsilon_{11} \\ \varepsilon_{13}\end{array}\right], \quad$ i.e. $[\sigma]=[\bar{C}][\varepsilon]$

where we denote: the stress tensor $[\sigma]$; the strain tensor $[\varepsilon]$. Furthermore, in Eq. (1), constitutive unidimensional laws are given by the elastic stiffness tensor $[\bar{C}]$.

Taking into account the classic assumption $\sigma_{22}=\sigma_{33}=0$ (transverse normal stresses are negligible), the longitudinal modulus is expressed from the three dimensional constitutive laws by

$\bar{C}_{11}=C_{11}-2 C_{12}^{2} /\left(C_{23}+C_{33}\right)$

where $C_{i j}$ are orthotropic three-dimensional elastic moduli. We also have $\bar{C}_{55}=C_{55}$.
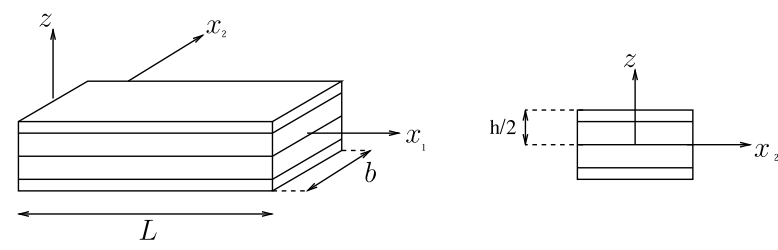

Fig. 1. The laminated beam and co-ordinate system 
Table 1

Principal notations

Table of principal notation

\begin{tabular}{ll}
\hline$[\sigma]$ & Stress tensor \\
{$[\varepsilon]$} & Strain tensor \\
$C_{i j}$ & 3D elastic stiffness modulus \\
$\bar{C}_{i j}$ & 1D elastic stiffness modulus \\
{$\left[K_{u u}^{e}\right]$} & Elementary stiffness matrix \\
{$\left[M_{u u}^{e}\right]$} & Elementary mass matrix \\
{$\left[\mathscr{E}_{u}\right],\left[\mathscr{E}_{s}\right]$} & Generalized displacement vector \\
{$[N],[B]$} & Interpolation functions vector and derivatives \\
& vector \\
{$\left[q_{e}\right]$} & Degrees of freedom elementary vector \\
$\vec{u}$ & Displacement vector \\
$L$ & Length of the beam \\
$b$ & Width of the beam \\
$h$ & Height of the beam \\
$\mathrm{NC}$ & Number of layers \\
$N$ & Number of elements \\
$t$ & Time \\
$S$ & Length to thickness ratio \\
$\alpha_{k}$ & Continuity coefficient for the Sin-c model \\
$\left(\delta_{i}^{k}, \beta_{i}^{k}\right)_{i=1,2,3}$ & Continuity coefficients for the SinRef-c model \\
Sin & Sinus model without continuity requirements \\
$\operatorname{Sin}-\mathrm{c}$ & Sinus model with continuity requirements \\
SinRef-c & Refined sinus model with continuity \\
& requirements \\
\hline & \\
\hline
\end{tabular}

\subsubsection{The weak form of the boundary value problem}

Using the above matrix notations and for admissible virtual displacement $\vec{u}^{*} \in U^{*}$, the variational principle is given by

Find $\vec{u} \in U$ (space of admissible displacements) such as

$$
\begin{aligned}
& -\int_{\mathscr{B}}\left[\varepsilon\left(\vec{u}^{*}\right)\right]^{\mathrm{T}}[\sigma(\vec{u})] \mathrm{d} \mathscr{B}+\int_{\mathscr{B}}\left[u^{*}\right]^{\mathrm{T}}[f] \mathrm{d} \mathscr{B} \\
& \quad+\int_{\partial \mathscr{B}_{F}}\left[u^{*}\right]^{\mathrm{T}}[F] \mathrm{d} \partial \mathscr{B}=\int_{\mathscr{B}} \rho\left[u^{*}\right]^{\mathrm{T}}[\ddot{u}] \mathrm{d} \mathscr{B} \quad \forall \vec{u}^{*} \in U^{*}
\end{aligned}
$$

where $[f]$ and $[F]$ are the prescribed body and surface forces applied on $\partial \mathscr{B}_{F}, \varepsilon\left(\vec{u}^{*}\right)$ is the virtual strain, and $\rho$ is the mass density.

Eq. (3) is a classical starting point for finite element approximations.

\subsection{The displacement field for laminated beams}

Based on the sinus function (see [36]), a family of models is presented. In the following, we can distinguish:

- the sinus model (denoted Sin) without continuity of the transverse shear stress on the interface between the layers and also free conditions,

- the sinus model (denoted Sin-c) which takes into account the continuity conditions between layers of the laminate for both displacements and transverse shear stress, and the free conditions on the upper and lower surfaces owing to the heaviside function,

- the refined sinus model (denoted SinRef-c) where the refinement is added in each layer.
These three models are based on various works on beams, plates and shells, cf. Refs. [27,28,36-38].

\subsubsection{Kinematic for laminated/sandwich beams: the sinus model}

The kinematics of the sinus model is reminded as follows (with $\left.w^{\prime}=\partial w / \partial x_{1}\right)$ :

$$
\left\{\begin{aligned}
u_{1}\left(x_{1}, x_{2}, z, t\right)= & u\left(x_{1}, t\right)-z w\left(x_{1}, t\right)^{\prime} \\
& +f(z)\left(\omega_{3}\left(x_{1}, t\right)+w\left(x_{1}, t\right)^{\prime}\right) \\
u_{3}\left(x_{1}, x_{2}, z, t\right)= & w\left(x_{1}, t\right)
\end{aligned}\right.
$$

where $t$ is the time. In the context of the sinus model, we have:

$f(z)=\frac{h}{\pi} \sin \frac{\pi z}{h}$

and this function will represent the transverse shear strain distribution due to bending by its derivative.

In the classic approach, $w$ is bending deflection following the $z$ direction. $u$ is associated with the uniform extension of the cross section of the beam along the central line. And, $\omega_{3}$ is the shear bending rotation around the $z$ axis.

From Eq. (4), classical beam models can be deduced:

- Navier Bernoulli

$f(z)=0$

- Timoshenko

$f(z)=z$

- sinus model

$f(z)=\frac{h}{\pi} \sin \frac{\pi z}{h}$

Hence, it is obvious that lateral boundary conditions are satisfied in bending and it is not necessary to introduce transverse shear correction factors.

\subsubsection{Kinematic for laminated/sandwich beams: the sinus model with a heaviside function}

Here, the sinus model is presented with the Heaviside function which allows to impose the continuity of the transverse shear stress on the interface between two layers, and the free conditions on the upper and lower surfaces. The displacement field is assumed to be of the particular form:

$$
\left\{\begin{aligned}
u_{1}\left(x_{1}, x_{2}, z, t\right)= & u\left(x_{1}, t\right)+z v\left(x_{1}, t\right)+g(z) v_{2}\left(x_{1}, t\right) \\
& +f(z)\left(\omega_{3}\left(x_{1}, t\right)+w\left(x_{1}, t\right)^{\prime}\right) \\
& +\sum_{k=1}^{(\mathrm{NC})-1} v_{k}^{c}\left(x_{1}, t\right)\left(z-z_{k}\right) H\left(z-z_{k}\right) \\
u_{3}\left(x_{1}, x_{2}, z, t\right)= & w\left(x_{1}, t\right)
\end{aligned}\right.
$$

where $H$ is the Heaviside function defined by

$$
\begin{cases}H\left(z-z_{k}\right)=1 & \text { if } z \geqslant z_{k} \\ H\left(z-z_{k}\right)=0 & \text { if not }\end{cases}
$$


and

$g(z)=\frac{h}{\pi} \cos \left(\frac{\pi z}{h}\right)$

The coordinate system is precised on Fig. 2.

From this displacement field, continuity conditions and boundary conditions yield to the following expression:

$$
\left\{\begin{aligned}
u_{1}\left(x_{1}, x_{2}, z, t\right)= & u\left(x_{1}, t\right)-z w\left(x_{1}, t\right)^{\prime}+f(z)\left(\omega_{3}\left(x_{1}, t\right)+w\left(x_{1}, t\right)^{\prime}\right) \\
& +\sum_{k=1}^{(\mathrm{NC})-1} \alpha_{k}\left\{-\frac{1}{2} z+\frac{1}{2} g(z)+\left(z-z_{k}\right) H\left(z-z_{k}\right)\right\} \\
& \times\left(\omega_{3}\left(x_{1}, t\right)+w\left(x_{1}, t\right)^{\prime}\right) \\
u_{3}\left(x_{1}, x_{2}, z, t\right)= & w\left(x_{1}, t\right)
\end{aligned}\right.
$$

where $\alpha_{k}$ are the continuity coefficients deduced from the physical relations, they depend on the shear modulus. The calculation of these coefficients are detailed in Section A. They are deduced from a linear system.

It should be noticed that the number of generalized displacements is reduced to 3 , and is independent from the number of layers.

\subsubsection{Kinematic for laminated/sandwich beams: the refined sinus model}

This part is based on both

- various works on beams, plates and shells, cf. Refs. [27,36-38] concerning the refined theory,

- the so-called 1,2-3 double-superposition theory developed by Li and Liu [29].

It also follows works about local-global approach studied in $[39,40]$.

Hence, in our approach, the displacement field is assumed to be of the following particular form:

$$
\left\{\begin{aligned}
u_{1}\left(x_{1}, x_{2}, z, t\right)= & u\left(x_{1}, t\right)-z w\left(x_{1}, t\right)^{\prime}+f(z)\left(\omega_{3}\left(x_{1}, t\right)+w\left(x_{1}, t\right)^{\prime}\right) \\
& +\sum_{k=1}^{\mathrm{NC}}\left(\bar{u}_{\mathrm{loc}}^{(k)}\left(x_{1}, z, t\right)+\hat{u}_{\mathrm{loc}}^{(k)}\left(x_{1}, z, t\right)\right) \\
& \times\left(H\left(z-z_{k}\right)-H\left(z-z_{k+1}\right)\right) \\
u_{3}\left(x_{1}, x_{2}, z, t\right)= & w\left(x_{1}, t\right)
\end{aligned}\right.
$$

where $H$ is the Heaviside function and

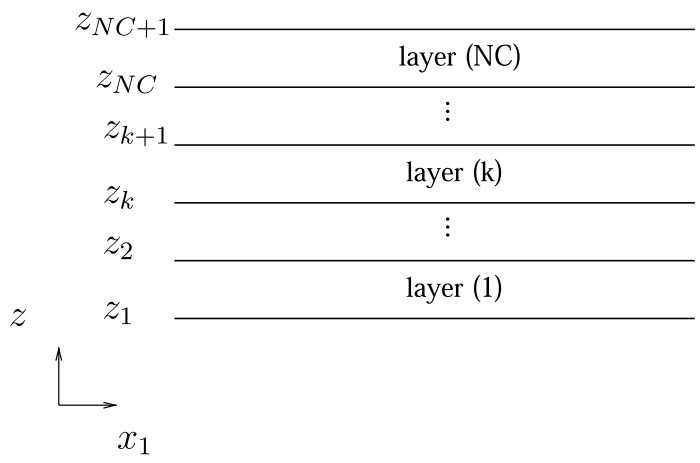

Fig. 2. coordinate system of laminated beam. $\zeta_{k}=a_{k} z-b_{k}, \quad a_{k}=\frac{2}{z_{k+1}-z_{k}}, \quad b_{k}=\frac{z_{k+1}+z_{k}}{z_{k+1}-z_{k}}$.

The local functions $\bar{u}_{\text {loc }}^{(k)}$ and $\hat{u}_{\text {loc }}^{(k)}$ based on the Legendre polynomial can be written as

$$
\left\{\begin{array}{l}
\bar{u}_{\mathrm{loc}}^{(k)}\left(x_{1}, z, t\right)=\zeta_{k} u_{31}^{k}\left(x_{1}, t\right)+\left(-\frac{1}{2}+\frac{3 \zeta_{k}^{2}}{2}\right) u_{32}^{k}\left(x_{1}, t\right) \\
\hat{u}_{\mathrm{loc}}^{(k)}\left(x_{1}, z, t\right)=\left(-\frac{3 \zeta_{k}}{2}+\frac{5 \zeta_{k}^{3}}{2}\right) u_{33}^{k}\left(x_{1}, t\right)
\end{array}\right.
$$

Remark. These Legendre polynomials have the interesting following properties: if we note $A_{1}=\zeta_{k}, A_{2}=-\frac{1}{2}+\frac{3 \zeta_{k}^{2}}{2}$ and $A_{3}=-\frac{3 \zeta_{k}}{2}+\frac{5 \zeta_{k}^{3}}{2}$

$\int_{-1}^{+1} A_{i} \mathrm{~d} \zeta_{k}=0, \quad i=1,2,3$ and $\int_{-1}^{+1} A_{i} A_{j} \mathrm{~d} \zeta_{k}=0, \quad i \neq j$

At this stage, $3 \times \mathrm{NC}+3$ generalized displacements are included in Eqs. (9) and (10). The following part is dedicated to the obtention of relations between kinematic unknowns from:

- lateral boundary conditions,

- interlaminar continuity conditions (displacement, transverse shear stress).As the previous model, it should be noted that the physical meaning is kept.

\subsubsection{Continuity conditions and free conditions for the refined sinus model}

From the displacement field Eq. (9), some continuity conditions on displacements and interlaminar stress must be imposed. For an interface layer $k \in\{2, \ldots, N C\}$, we have:

- displacement continuity conditions as in [39] i.e.:

$\bar{u}_{\mathrm{loc}}^{(k)}\left(x_{1}, z_{k}, t\right)=\bar{u}_{\mathrm{loc}}^{(k-1)}\left(x_{1}, z_{k}, t\right), \quad k=2, \ldots, \mathrm{NC}$

$\hat{u}_{\text {loc }}^{(k)}\left(x_{1}, z_{k}, t\right)=\hat{u}_{\text {loc }}^{(k-1)}\left(x_{1}, z_{k}, t\right), \quad k=2, \ldots, \mathrm{NC}$

- transverse shear stress continuity between two adjacent layers:

$\sigma_{13}^{(k)}\left(x_{1}, z_{k}^{+}\right)=\sigma_{13}^{(k-1)}\left(x_{1}, z_{k}^{-}\right), \quad k=2, \ldots, \mathrm{NC}$

So, $3 * \mathrm{NC}-3$ conditions are imposed, which allow to reduce the number of unknowns to six generalized displacements.

Free conditions of the transverse shear stress on the upper and lower surfaces must also be verified. So, we have:

$\sigma_{13}^{(1)}\left(x_{1}, z=-\frac{h}{2}\right)=0 \quad$ and $\quad \sigma_{13}^{(\mathrm{NC})}\left(x_{1}, z=\frac{h}{2}\right)=0$

Finally, the number of generalized displacements is reduced to 4 , which is independent from the number of layers. 


\subsubsection{Relation between the generalized displacements}

Using the displacement notation introduced in Eq. (10), the conditions Eqs. (12)-(15) can be written under the following form:

$[A]\{v\}=\{b\} u_{31}^{1}\left(x_{1}, t\right)+\{c\}\left(\omega_{3}\left(x_{1}, t\right)+w\left(x_{1}, t\right)^{\prime}\right)$

where $[A]$ is a $(3 * \mathrm{NC}-1) \times(3 * \mathrm{NC}-1)$ matrix, $\{v\}^{\mathrm{T}}=\left\{u_{32}^{1} u_{33}^{1} \cdots u_{31}^{j} u_{32}^{j} u_{33}^{j} \cdots u_{31}^{\mathrm{NC}} u_{32}^{\mathrm{NC}} u_{33}^{\mathrm{NC}}\right\}^{\mathrm{T}}, \mathrm{a}(3 * \mathrm{NC}-1)$ vector, and $\{b\},\{c\}$ two $(3 * \mathrm{NC}-1)$ vectors.

From the resolution of this linear system, relations between $u_{31}^{j}(j \neq 1), u_{32}^{j}, u_{33}^{j}, j=1, \ldots, \mathrm{NC}$ and $u_{31}^{1}$ can be deduced. This relation can be written under the following form:

$$
\begin{aligned}
& {\left[F_{s}(z)\right]=\left[\begin{array}{ccc}
1 & 0 & -z+\left(f(z)+S_{\beta}(z)\right) \\
0 & \left(f(z)_{, 3}+S_{\beta}(z)_{, 3}\right) & 0
\end{array}\right.} \\
& \left\{\begin{aligned}
u_{31}^{j}\left(x_{1}, t\right)= & \beta_{1}^{j}\left(\omega_{3}\left(x_{1}, t\right)+w\left(x_{1}, t\right)^{\prime}\right) \\
& +\delta_{1}^{j} u_{31}^{1}\left(x_{1}, t\right), \quad j=1, \ldots, \mathrm{NC} \quad\left(\delta_{1}^{1}=1, \beta_{1}^{1}=0\right) \\
u_{32}^{j}\left(x_{1}, t\right)= & \beta_{2}^{j}\left(\omega_{3}\left(x_{1}, t\right)+w\left(x_{1}, t\right)^{\prime}\right) \\
& +\delta_{2}^{j} u_{31}^{1}\left(x_{1}, t\right), \quad j=1, \ldots, \mathrm{NC} \\
u_{33}^{j}\left(x_{1}, t\right)= & \beta_{3}^{j}\left(\omega_{3}\left(x_{1}, t\right)+w\left(x_{1}, t\right)^{\prime}\right) \\
& +\delta_{3}^{j} u_{31}^{1}\left(x_{1}, t\right), \quad j=1, \ldots, \mathrm{NC}
\end{aligned}\right.
\end{aligned}
$$

where $\delta_{1}^{j}, \delta_{2}^{j}, \delta_{3}^{j}$, and $\beta_{1}^{j}, \beta_{2}^{j}, \beta_{3}^{j}$ are the coefficients deduced from Eq. (16).

Finally, the four unknowns become $u, w, \omega_{3}$, and $u_{31}^{1}$.

\subsubsection{Expression of strains}

Matrix notations can be easily defined using a generalized displacement vector as

$[u]^{\mathrm{T}}=\left[F_{u}(z)\right]\left[\mathscr{E}_{u}\right]$

with $\left[\mathscr{E}_{u}\right]^{\mathrm{T}}=\left[\begin{array}{llllllll}u & \vdots & w & w_{, 1} & \vdots & \omega_{3} & \vdots & u_{31}^{1}\end{array}\right]$

and $\left[F_{u}(z)\right]$ is depending on the normal coordinate $z$. Its expression is given below:

$\left[F_{u}(z)\right]=\left[\begin{array}{ccccc}1 & 0 & F_{u 13}(z) & F_{u 14}(z) & F_{u 15}(z) \\ 0 & 1 & 0 & 0 & 0\end{array}\right]$

where

$F_{u 13}(z)=-z+f(z)+S_{\beta}(z)$

$F_{u 14}(z)=f(z)+S_{\beta}(z)$

$F_{u 15}(z)=S_{\delta}(z)$

and

$S_{\beta}(z)=\sum_{k=1}^{\mathrm{NC}}\left(\zeta_{k} \beta_{1}^{k}+\left(-\frac{1}{2}+\frac{3 \zeta_{k}^{2}}{2}\right) \beta_{2}^{k}+\left(-\frac{3 \zeta_{k}}{2}+\frac{5 \zeta_{k}^{3}}{2}\right) \beta_{3}^{k}\right) \Delta H(k, k+1)$

$S_{\delta}(z)=\sum_{k=1}^{\mathrm{NC}}\left(\zeta_{k} \delta_{1}^{k}+\left(-\frac{1}{2}+\frac{3 \zeta_{k}^{2}}{2}\right) \delta_{2}^{k}+\left(-\frac{3 \zeta_{k}}{2}+\frac{5 \zeta_{k}^{3}}{2}\right) \delta_{3}^{k}\right) \Delta H(k, k+1)$

with $\Delta H(k, k+1)=H\left(z-z_{k}\right)-H\left(z-z_{k+1}\right)$.
The strains for the symmetric laminated beam element are:

$$
\begin{aligned}
& \varepsilon_{11}=u_{, 1}-z w_{, 11}+\left(f(z)+S_{\beta}(z)\right)\left(w_{, 11}+\omega_{3,1}\right)+S_{\delta}(z) u_{31,1}^{1} \\
& \gamma_{13}=\left(f(z)_{, 3}+S_{\beta}(z)_{, 3}\right)\left(w_{, 1}+\omega_{3}\right)+S_{\delta}(z)_{, 3} u_{31}^{1}
\end{aligned}
$$

These expression can be described using a matrix notation:

$$
\begin{aligned}
& {[\varepsilon]=\left[F_{s}(z)\right]\left[\mathscr{E}_{s}\right] \quad \text { with }} \\
& {\left[\mathscr{E}_{s}\right]^{\mathrm{T}}=\left[\begin{array}{llllllllll}
u_{, 1} & \vdots & w_{, 1} & w_{, 11} & \vdots & \omega_{3} & \omega_{3,1} & \vdots & u_{31}^{1} & u_{31,1}^{1}
\end{array}\right]}
\end{aligned}
$$

$$
\text { and }\left[F_{s}(z)\right] \text { is depending on the normal coordinate } z \text {. Its }
$$
expression is given below:

\subsubsection{Matrix expression for the weak form}

From the weak form of the boundary value problem Eq. (3), and using Eqs. (21) and (22), an integration throughout the cross-section is performed analytically in order to obtain an unidimensional formulation. Therefore, the first left term of Eq. (3) can be written under the following form:

$$
\begin{aligned}
& \int_{\mathscr{B}}\left[\varepsilon\left(\vec{u}^{*}\right)\right]^{\mathrm{T}}[\sigma(\vec{u})] \mathrm{d} \mathscr{B}=\int_{0}^{L}\left[\mathscr{E}_{s}^{*}\right]^{\mathrm{T}}[k]\left[\mathscr{E}_{s}\right] \mathrm{d} x_{1} \quad \text { with } \\
& {[k]=\int_{\Omega}\left[F_{s}(z)\right]^{\mathrm{T}}[\bar{C}]\left[F_{s}(z)\right] \mathrm{d} \Omega}
\end{aligned}
$$

where $[\bar{C}]$ is the constitutive unidimensional law given in Section 2.1.1, and $\Omega$ represents the cross-section $\left[-\frac{h}{2} \leqslant z \leqslant \frac{h}{2}\right] \times\left[-\frac{b}{2} \leqslant x_{2} \leqslant \frac{b}{2}\right]$.

The same calculations for the right member of Eq. (3) using Eqs. (18) and (19) give:

$$
\begin{aligned}
& \int_{\mathscr{B}} \rho\left[u^{*}\right]^{\mathrm{T}}[\ddot{u}] \mathrm{d} \mathscr{B}=\int_{0}^{L}\left[\mathscr{E}_{u}^{*}\right]^{\mathrm{T}}[m]\left[\ddot{\mathscr{E}}_{u}\right] \mathrm{d} x_{1} \quad \text { with } \\
& {[m]=\int_{\Omega} \rho\left[F_{u}(z)\right]^{\mathrm{T}}\left[F_{u}(z)\right] \mathrm{d} \Omega}
\end{aligned}
$$

In Eq. (23) and (24), the matrices $[k]$ and $[m]$ are the integration throughout the cross-section of the beam material characteristics. The interest of the Legendre polynomials choice can be emphasized in the calculation of the matrices $[k]$ and $[m]$ owing to their properties of orthogonality (cf. Eq. (11)).

\subsection{The finite element approximation}

This section is dedicated to the finite element approximation of the generalized displacement, see matrices $\left[\mathscr{E}_{s}\right]$, $\left[\mathscr{E}_{s}^{*}\right], \quad\left[\mathscr{E}_{u}\right]$, and $\left[\mathscr{E}_{u}^{*}\right]$, Eqs. (21) and (18). It is briefly 
described, and the reader can obtain a detailed description in [28].

\subsubsection{The geometric approximation}

Given the displacement field constructed above for sandwich and laminated beams, a corresponding finite element is developed in order to analyze the behaviour of laminated beam structures under combined loads. Let us consider the $e$ th element $L_{e}^{h}$ of the mesh $\cup L_{e}^{h}$. This element has three nodes, denoted by $\left(g_{j}\right)_{j=1,2,3}$, see Fig. 3 . A point with coordinate $x_{1}$ on the central line of the beam will be as follows:

$x_{1}(\xi)=\sum_{j=1}^{2} N l_{j}(\xi) x_{1}^{e}\left(g_{j}\right)$

where $N l_{j}(\xi)$ are Lagrange linear interpolation functions and $x_{1}^{e}\left(g_{j}\right)$ are Cartesian coordinates (measured along the $x_{1}$ axis) of the node $g_{j}$ of the element $L_{e}^{h}$. $\xi$ is an isoparametric or reduced coordinate and its variation domain is $[-1,1]$.

\subsubsection{Interpolation for the bending-traction beam element}

The finite element approximations of the assumed displacement field components are hereafter symbolically written as $u_{i}^{h}\left(x_{1}, x_{2}, z\right)$ where the superscript $h$ refers to the mesh $\cup L_{e}^{h}$.

From the kinematics (see Eq. (9)), the transverse displacement $w^{h}$ must be $C^{1}$-continuous; whereas the rotation $\omega_{3}^{h}$, the extension displacement $u^{h}$ and $u_{31}^{1}$ can be only $C^{0}$ continuous. Therefore, the generalized displacement $w^{h}$ is interpolated by the Hermite cubic functions $N h_{j}(\xi)$.

According to the transverse shear locking phenomena, the other shear bending generalized displacements, rotation $\omega_{3}^{h}$, are interpolated by Lagrange quadratic functions denoted $N q_{j}(\xi)$. This choice allows the same order of interpolation for both $w_{1}^{h}$ and $\omega_{3}^{h}$ in the corresponding transverse shear strain components due to bending, and enables to avoid transverse shear locking using the field compatibility approach, see [41].

Finally, traction $u^{h}$ and $u_{31}^{1}$ are interpolated by Lagrange quadratic functions.

\subsubsection{Elementary matrices}

In the previous section, all the finite element mechanical approximations were defined, and elementary rigidity $\left[K_{u u}^{e}\right]$ and mass $\left[M_{u u}^{e}\right]$ matrices can be deduced from Eqs. (23) and (24). It has the following expression:

$$
\begin{aligned}
& {\left[K_{u u}^{e}\right]=\int_{L_{e}}[B]^{\mathrm{T}}[k][B] \mathrm{d} L_{e}} \\
& {\left[M_{u u}^{e}\right]=\int_{L_{e}}[N]^{\mathrm{T}}[m][N] \mathrm{d} L_{e}}
\end{aligned}
$$

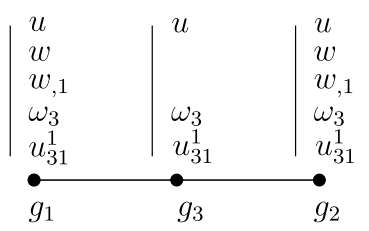

Fig. 3. Description of the laminated beam finite element d.o.f. where $[B]$ and $[N]$ are deduced expressing the generalized displacement vectors, see Eqs. (21) and (18), from the elementary vector of degrees of freedom (dof) denoted $\left[q_{e}\right]$ by

$\left[\mathscr{E}_{s}\right]=[B]\left[q_{e}\right], \quad\left[\mathscr{E}_{u}\right]=[N]\left[q_{e}\right]$

The matrices $[B]$ and $[N]$ contain only the interpolation functions, their derivatives and the jacobian components. The same technique can be used defining the elementary mechanical load vector, denoted $\left[B_{u}^{e}\right]$, but it is not detailed here.

\section{Results and discussions}

In this section, several static and dynamic tests are presented validating our finite element and evaluating its efficiency.

\subsection{Static analysis}

The aim of the present investigation is to study the efficiency of this new element to analyze the flexural behaviour of highly inhomogeneous sandwich and laminated beams for static mechanical problems. The results are compared with the sinus model (denoted Sin), the sinus model with heaviside function denoted Sin-c (see Section 2.2.2), and reference solution (exact solution [15] or commercial code ANSYS). To evaluate the performance of the element in bending, the considered cases are given in the three following sections.

\subsubsection{Properties of the finite element}

Before proceeding to the detailed analysis, numerical computations are carried out for the rank of the element (spurious mode), convergence properties and the effect of aspect ratio (shear locking).

The test is about simply supported symmetric composite beams. It is detailed below:

geometry: composite cross-ply beam $\left(0^{\circ} / 90^{\circ} / 0^{\circ}\right)$ and length to thickness ratio $S=20\left(S=\frac{L}{h}\right)$; half of the beam is meshed. All layers have the same thickness.

boundary conditions: simply supported beam subjected to sinusoidal load $q=q_{0} \sin \frac{\pi x_{1}}{L}$.

material properties:

$E_{L}=172.4 \mathrm{GPa}, \quad E_{T}=6.895 \mathrm{GPa}, \quad G_{L T}=3.448 \mathrm{GPa}$

$G_{T T}=1.379 \mathrm{GPa}, \quad v_{L T}=v_{T T}=0.25$

where $L$ refers to the fiber direction, $T$ refers to the normal direction. This element has a proper rank without any spurious energy modes when exact integration is applied to obtain all the stiffness matrices (see [28]). There is also no need to use shear correction factors here, as the transverse strain is represented by a cosine function. 
Table 2

$\bar{\sigma}_{13}(0,0), w_{m}$ for different number of dofs: mesh convergence study - three layers $\left(0^{\circ} / 90^{\circ} / 0^{\circ}\right)-S=20$

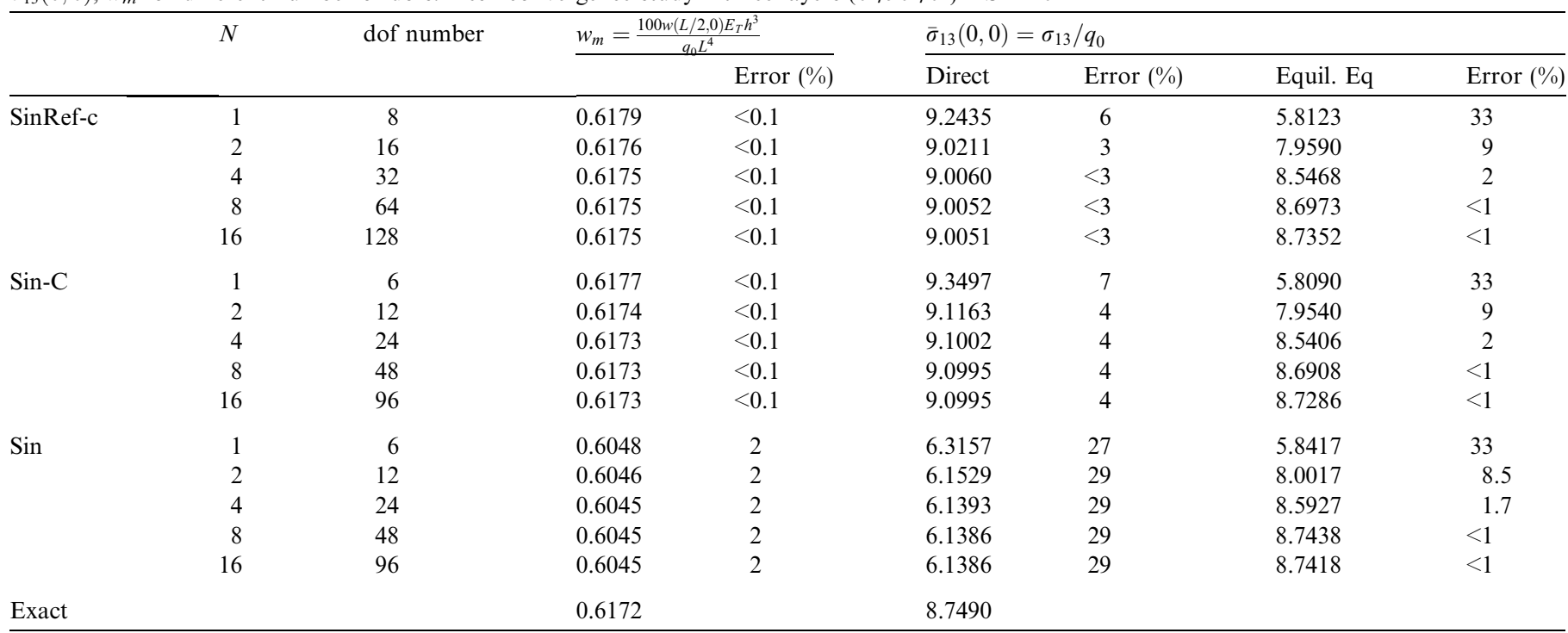

Table 2 gives the convergence of the family of sinus models for the transverse displacement and the transverse shear stress for $S=20$. For this last component, two results are available: (a) from the constitutive relation (denoted direct); (b) using the equilibrium equation at the post-processing level i.e. $\sigma_{13}(z)=-\int_{-h / 2}^{z} \sigma_{11,1} \mathrm{~d} x_{3}$ (denoted Equil. Eq). It must be noticed that the deflection is less sensitive to the mesh than the shear stress and the convergence velocity is very high. Based on progressive mesh refinement, a $N=8$ mesh is adequate to model the laminated beam for a bending analysis. Moreover, the results obtained are in good agreement with the reference values with few elements. In particular, a $N=1$ mesh gives excellent result for the deflection. It should be noted that the sinus model gives poor results for the transverse shear stress calculated with the constitutive relation regardless of the mesh.

Considering various values for aspect ratio,the normalized displacement obtained at the middle of the simply supported composite beam is shown in Fig. 4 along with the exact solution [42], and they are found to be in excellent agreement. It is also inferred from Fig. 4 that the present element is free from shear locking phenomenon as the element is developed using a field compatibility approach.

\subsubsection{Bending analysis of laminated composite beam}

This test is about simply supported symmetric and antisymmetric composite beams from Reference [42]. It is detailed below:

geometry: composite cross-ply beam $\left(0^{\circ} / 90^{\circ} / 0^{\circ}\right)$ and $\left(0^{\circ} /\right.$ $90^{\circ}$ ) and length to thickness ratio from $S=4$ to $S=40$; half of the beam is meshed. All layers have the same thickness.

boundary conditions: simply supported beam subjected to sinusoidal load $q=q_{0} \sin \frac{\pi x_{1}}{L}$.

material properties:same properties as in Section 3.1.1.
The two layers case $\left(0^{\circ} / 90^{\circ}\right)$ is first presented. The numerical results for deflection, in-plane displacements, shear stress, and in-plane stress are given in Tables 3-5 with respect to span-to-thickness ratio: $S=4$ (thick), $S=20$ (moderately thick), $S=40$ (thin). The \% error with $S$ for the refined model, sinus model with continuity and sinus model without continuity are also compared in these tables. For the displacements, the refined sinus gives more precise results than the sinus models (Sin and Sin-c). The error is less than $0.1 \%$ for the deflection, and less than $5 \%$ for the in-plane displacement. Concerning the stresses, the improvement is also significant. In particular, the values of transverse shear stresses calculated from the constitutive relation are much better, and are in good agreement with the exact solution (cf. Table 4), excepted for a thick laminate. Again, the error for the Sin model is high.

The variation of normalized in-plane, inter-laminar shear stresses and in-plane and transverse displacements through the thickness $(S=4, S=20$ and $S=40)$ are

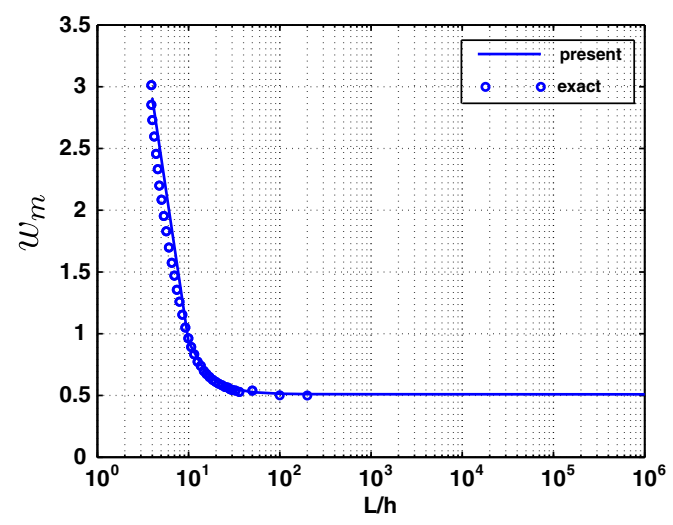

Fig. 4. variation of the non-dimensional maximum displacement $\left(w_{m}=100 w(L / 2,0) E_{T} h^{3} /\left(q_{0} L^{4}\right)\right)$ with respect to aspect ratio $S$ - three layers $\left(0^{\circ} / 90^{\circ} / 0^{\circ}\right)$; mesh $N=8$; SinRef-c model. 
Table 3

$\bar{u}(0, h / 2)$ and $\bar{w}(L / 2,0)$ for different values of $S$ - two layers $\left(0^{\circ} / 90^{\circ}\right)$

\begin{tabular}{|c|c|c|c|c|c|c|c|}
\hline \multirow[t]{2}{*}{$S$} & \multicolumn{7}{|l|}{$\bar{u}(0, h / 2)$} \\
\hline & SinRef-c & Error $(\%)$ & Sin-c & Error $(\%)$ & $\operatorname{Sin}$ & Error $(\%)$ & Exact \\
\hline 4 & 4.78 & 5 & 3.40 & 25 & 3.93 & 13.6 & 4.55 \\
\hline 20 & 486.20 & 0.2 & 479.02 & 1 & 482.52 & 0.5 & 485.15 \\
\hline 40 & 3858.7 & $<0.1$ & 3843.9 & 0.3 & 3858.16 & $<0.1$ & 3856.3 \\
\hline & $\bar{w}(L / 2,0)$ & & & & & & \\
\hline 4 & 4.6964 & $<0.1$ & 4.1811 & 11 & 4.403 & 6.2 & 4.6950 \\
\hline 20 & 2.7035 & $<0.1$ & 2.6837 & 0.7 & 2.6981 & 0.1 & 2.7027 \\
\hline 40 & 2.6400 & $<0.1$ & 2.6350 & 0.2 & 2.6436 & 0.1 & 2.6398 \\
\hline
\end{tabular}

Table 4

$\bar{\sigma}_{13}(0,-h / 4)$ (maxi) for different values of $S$ - two layers $\left(0^{\circ} / 90^{\circ}\right)$

\begin{tabular}{|c|c|c|c|c|c|c|c|c|c|c|c|c|c|}
\hline \multirow[t]{3}{*}{$S$} & \multicolumn{13}{|c|}{$\bar{\sigma}_{13}(0,-h / 4)$} \\
\hline & \multicolumn{4}{|c|}{ SinRef-c } & \multicolumn{4}{|l|}{ Sin-c } & \multicolumn{4}{|l|}{ Sin } & \multirow[t]{2}{*}{ Exact } \\
\hline & Direct & Error $(\%)$ & Equil. eq & Error $(\%)$ & Direct & Error $(\%)$ & Equil. eq & Error $(\%)$ & Direct & Error $(\%)$ & Equil. eq & Error $(\%)$ & \\
\hline 20 & 13.450 & 8 & 14.555 & 0.5 & 7.676 & 48 & 14.684 & $<0.1$ & 9.114 & 38 & 14.602 & 0.1 & 14.620 \\
\hline 40 & 26.940 & 8 & 29.165 & 0.5 & 15.372 & 48 & 29.197 & 0.4 & 18.243 & 38 & 29.180 & 0.4 & 29.324 \\
\hline
\end{tabular}

Table 5

$\bar{\sigma}_{11}(L / 2,-h / 2)$ for different values of $S-$ two layers $\left(0^{\circ} / 90^{\circ}\right)$

\begin{tabular}{|c|c|c|c|c|c|c|c|}
\hline \multirow[t]{2}{*}{$S$} & \multicolumn{7}{|c|}{$\bar{\sigma}_{11}(L / 2,-h / 2)$} \\
\hline & SinRef-c & Error $(\%)$ & Sin-c & Error $(\%)$ & Sin & Error $(\%)$ & Exact \\
\hline 4 & 31.9 & 6 & 33.5 & 11 & 33.3 & 11 & 30.0 \\
\hline 40 & 2803.1 & 0.3 & 2805.2 & 0.4 & 2751.7 & 1.4 & 2792.6 \\
\hline
\end{tabular}

presented in Figs. 5-9 for further comparison. It is seen from these figures that the new element performs quite well for thick beams as well as thin beams. It should be noted that the distribution of in-plane displacement and stress is similar to the exact Pagano solution regardless of the length to thickness ratio. The transverse shear stress obtained using the equilibrium equation gives excellent results, especially for the very thick beam $S=4$ (see Figs. 5 and 6 (left)). It must be noticed that for design application, the variation of the transverse shear stress deduced from the constitutive relation yields satisfactory distributions, without the computational cost at the post-processing level.

Then, the three layers $\left(0^{\circ} / 90^{\circ} / 0^{\circ}\right)$ case is evaluated. The results are summarized in Tables $6-8$ and represented on Figs. 10-14. Again, it should be noted that the refined sinus model improves the accuracy of the results for both displacements and stresses for thin and thick laminates. The error is less than $1 \%$ for in-plane and transverse displacements, and less than 3\% for stresses, whatever the length
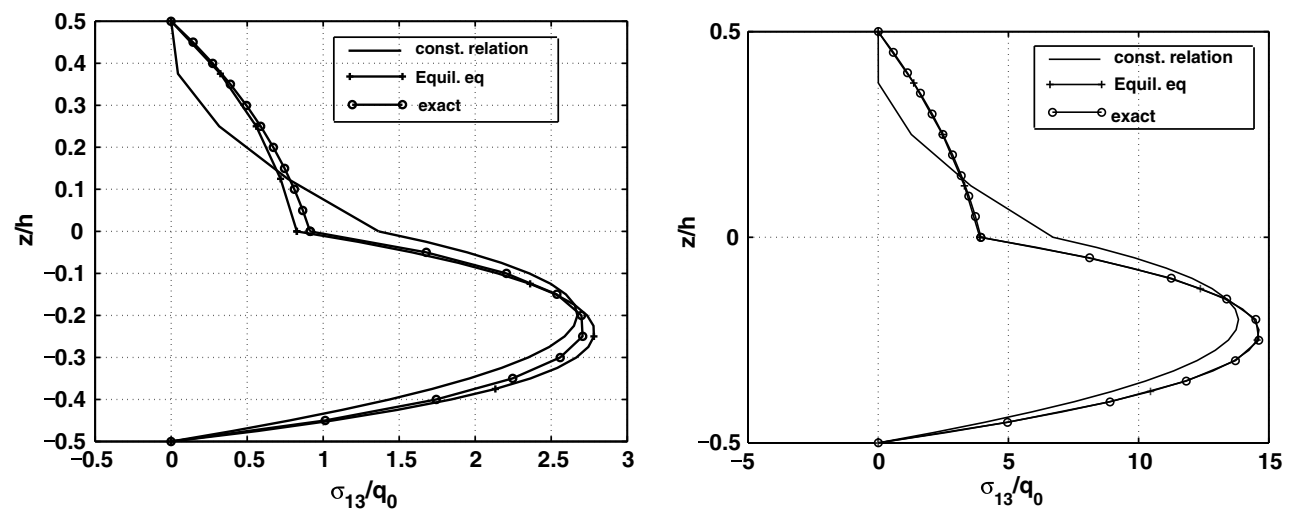

Fig. 5. Distribution of $\bar{\sigma}_{13}$ along the thickness $-S=4$ (left) and $S=20$ (right) - two layers $\left(0^{\circ} / 90^{\circ}\right)$-SinRef-c. 

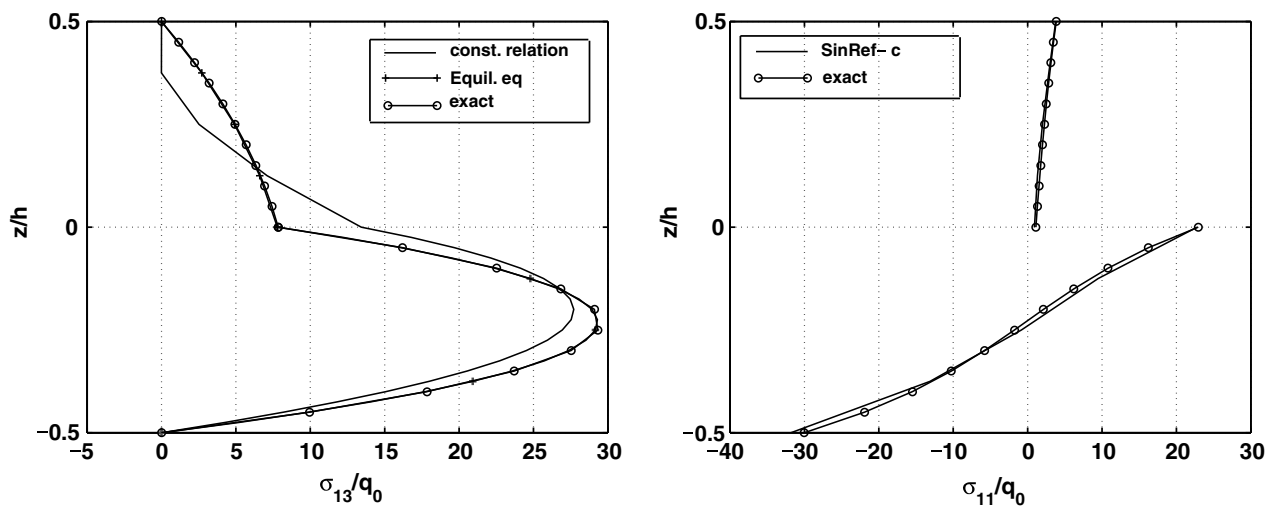

Fig. 6. Distribution of $\bar{\sigma}_{13} S=40$ (left) and $\bar{\sigma}_{11} S=4$ (right) along the thickness - two layers $\left(0^{\circ} / 90^{\circ}\right)$-SinRef-c.
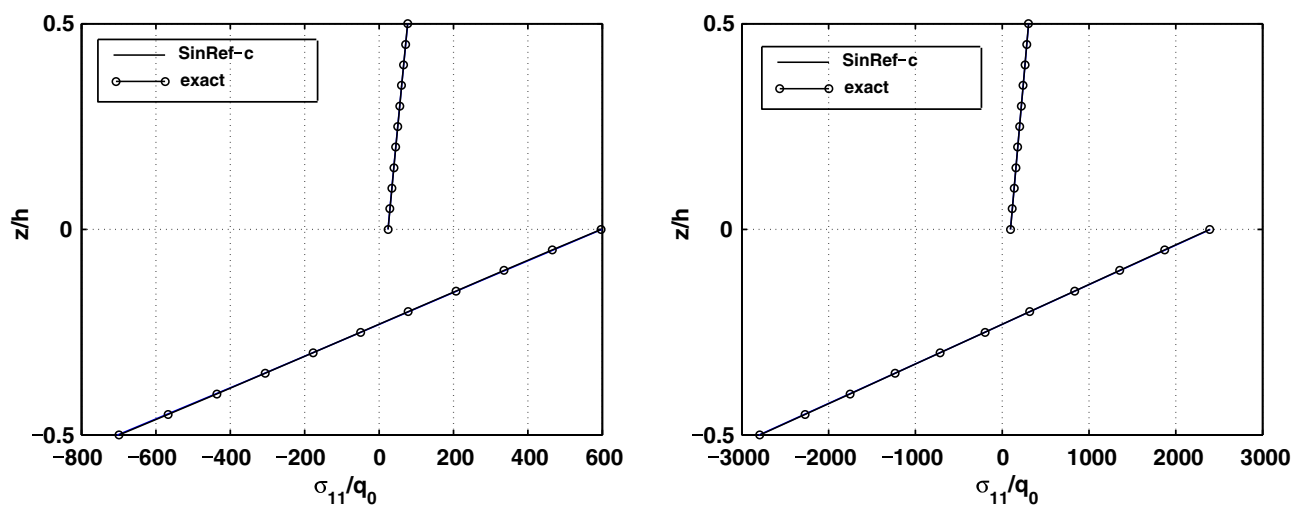

Fig. 7. Distribution of $\bar{\sigma}_{11}$ along the thickness $-S=20$ (left) and $S=40$ (right) - two layers $\left(0^{\circ} / 90^{\circ}\right)$-SinRef-c.
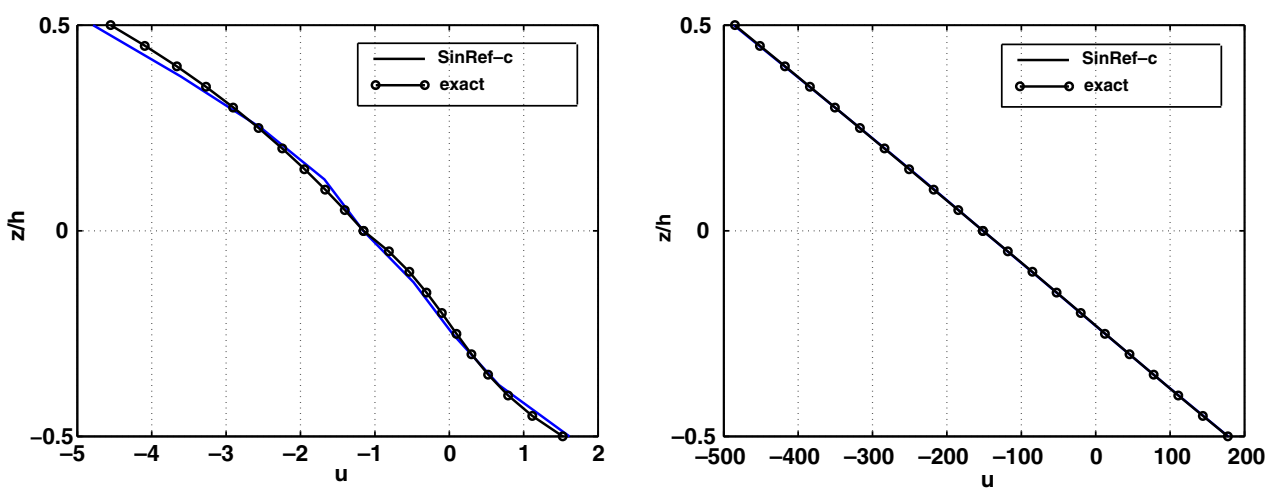

Fig. 8. Distribution of $\bar{u}$ along the thickness $-S=4$ (left) and $S=20$ (right) - two layers $\left(0^{\circ} / 90^{\circ}\right)$-SinRef-c.

to thickness ratio. The variation of the transverse shear stress calculated from the constitutive relation gives also excellent results.

\subsubsection{Bending analysis of sandwich beam [43]}

The three-point bending test is considered for a sandwich beam which has the following characteristics:

geometry: thickness $h=0.01 \mathrm{~m}$; The beam possesses three layers of the same thickness;

boundary conditions: simply supported beam under concentrated load at the middle of the beam $p=-100 \mathrm{~N} / \mathrm{m}$; material properties: face: $E_{\mathrm{f}}=6.9 E 10 \mathrm{~Pa}, v_{\mathrm{f}}=0.3$; core: $E_{\mathrm{c}}, v_{\mathrm{c}}=0.3$;

mesh: half of the beam with $N=8$;

Two examples are carried out:

case 1: $L / h=50 E_{\mathrm{c}}=0.001 E_{\mathrm{f}}$;

case 2: $L / h=50 E_{\mathrm{c}}=0.1 E_{\mathrm{f}}$;

Table 9 gives the deflection and stresses for the three different models. The comparison with ANSYS results shows that the two sinus models Sin-c and SinRef-c give accurate 


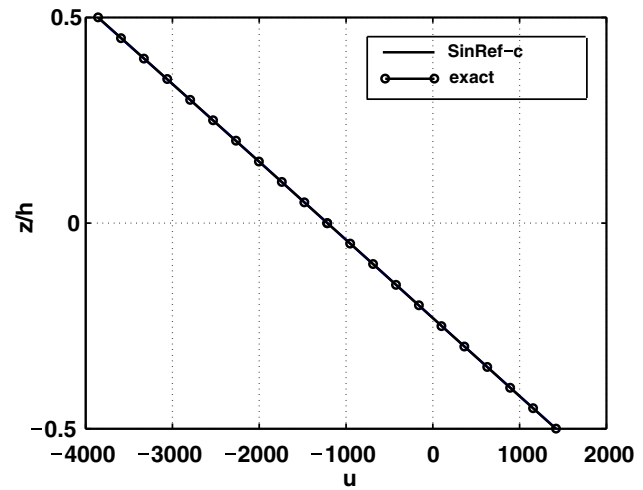

Fig. 9. Distribution of $\bar{u}$ along the thickness $-S=40$ - two layers $\left(0^{\circ} / 90^{\circ}\right)$-SinRef-c.

results for this example. The $\%$ error is less than $4 \%$ whatever the case is. On the other hand, the sinus model gives poor results when the value of the ratio $\frac{E_{\mathrm{f}}}{E_{\mathrm{c}}}$ is very high.

\subsection{Free-vibration test}

Some examples of sandwich and laminated beams are tested to evaluate these finite elements. The dynamic analyses are carried out in the free vibration case. It concerns simply supported beams with large range of length to thick- ness ratio. These examples are taken from [44,45,31]. The results are compared to the ANSYS solution with a very refined mesh.

\subsubsection{Convergence study for the SinRef-c model [31]}

First, a convergence study with respect to the mesh is carried out. A symmetric three layers beam is considered with an aspect ratio $S=10$. It is detailed below:

geometry: composite cross-ply beam $\left(0^{\circ} / 90^{\circ} / 0^{\circ}\right)$ and length to thickness ratio $S=10$, three layers of equal thickness.

boundary conditions: free vibration of a simply supported beam.

\section{material properties:}

$E_{L}=181 \mathrm{GPa}, \quad E_{T}=10.3 \mathrm{GPa}, \quad G_{L T}=7.17 \mathrm{GPa}$

$G_{T T}=2.87 \mathrm{GPa}, \quad v_{L T}=0.25, \quad v_{T T}=0.33$

Table 10 shows the quick convergence, and a $N=8$ mesh seems to be sufficient to model the laminated composite beam for a dynamic analysis.

The same study is carried out with the commercial code ANSYS [46]. A very refined mesh is considered as a reference. The mesh of 1275 dofs is shown in Fig. 15.

Table 6

$\bar{w}(L / 2,0)$ and $\bar{u}(0, h / 2)$ for different values of $S-3$ layers $\left(0^{\circ} / 90^{\circ} / 0^{\circ}\right)$

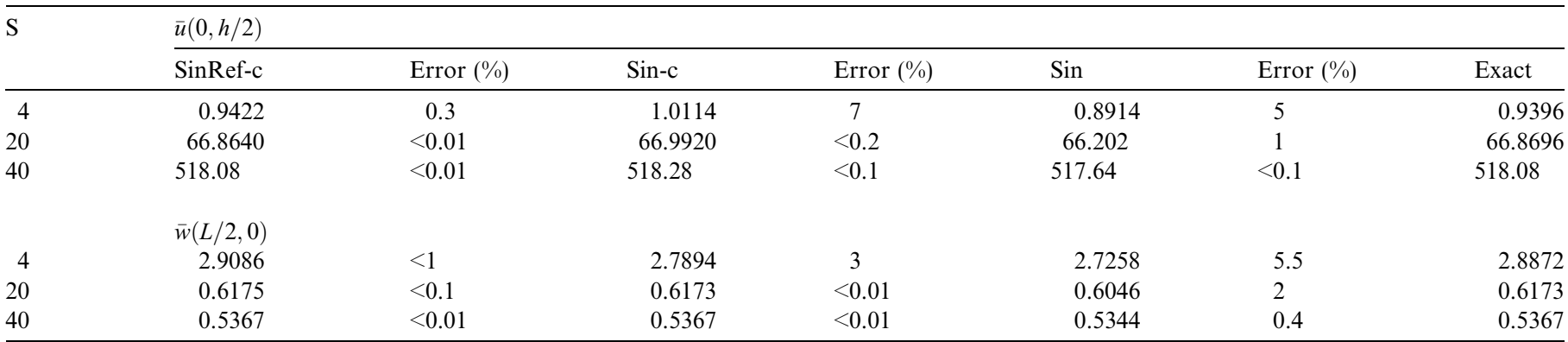

Table 7

$\bar{\sigma}_{13}(0,0)$ for different values of $S-3$ layers $\left(0^{\circ} / 90^{\circ} / 0^{\circ}\right)$

\begin{tabular}{|c|c|c|c|c|c|c|c|c|c|c|c|c|c|}
\hline \multirow[t]{3}{*}{$\mathrm{S}$} & \multicolumn{13}{|l|}{$\bar{\sigma}_{13}(0,0)$} \\
\hline & \multicolumn{4}{|l|}{ SinRef-c } & \multicolumn{4}{|l|}{ Sin-c } & \multicolumn{4}{|l|}{$\operatorname{Sin}$} & \multirow[t]{2}{*}{ Exact } \\
\hline & Direct & Error $(\%)$ & Equil. eq & Error $(\%)$ & Direct & Error $(\%)$ & Equil. eq & Error $(\%)$ & Direct & Error $(\%)$ & Equil. eq & Error $(\%)$ & \\
\hline 20 & 9.0052 & 2.9 & 8.6973 & $<1$ & 9.099 & 4 & 8.691 & $<1$ & 6.138 & 29 & 8.743 & $<0.1$ & 8.7490 \\
\hline 40 & 18.184 & 3 & 17.539 & $<1$ & 18.302 & 4 & 17.536 & $<1$ & 12.299 & 30 & 17.563 & 0.4 & 17.634 \\
\hline
\end{tabular}

Table 8

$\bar{\sigma}_{11}(L / 2, h / 2)$ for different values of $S$ - three layers $\left(0^{\circ} / 90^{\circ} / 0^{\circ}\right)$

\begin{tabular}{|c|c|c|c|c|c|c|c|}
\hline \multirow[t]{2}{*}{$\mathrm{S}$} & \multicolumn{7}{|c|}{$\bar{\sigma}_{11}(L / 2, h / 2)$} \\
\hline & SinRef-c & Error $(\%)$ & Sin-c & Error $(\%)$ & $\operatorname{Sin}$ & Error $(\%)$ & Exact \\
\hline 4 & 18.6 & 1 & 19.9 & 5 & 19.7 & 5 & 18.8 \\
\hline 40 & 1023.0 & $<0.5$ & 1023.5 & 0.4 & 1013.6 & 0.6 & 1019.8 \\
\hline
\end{tabular}



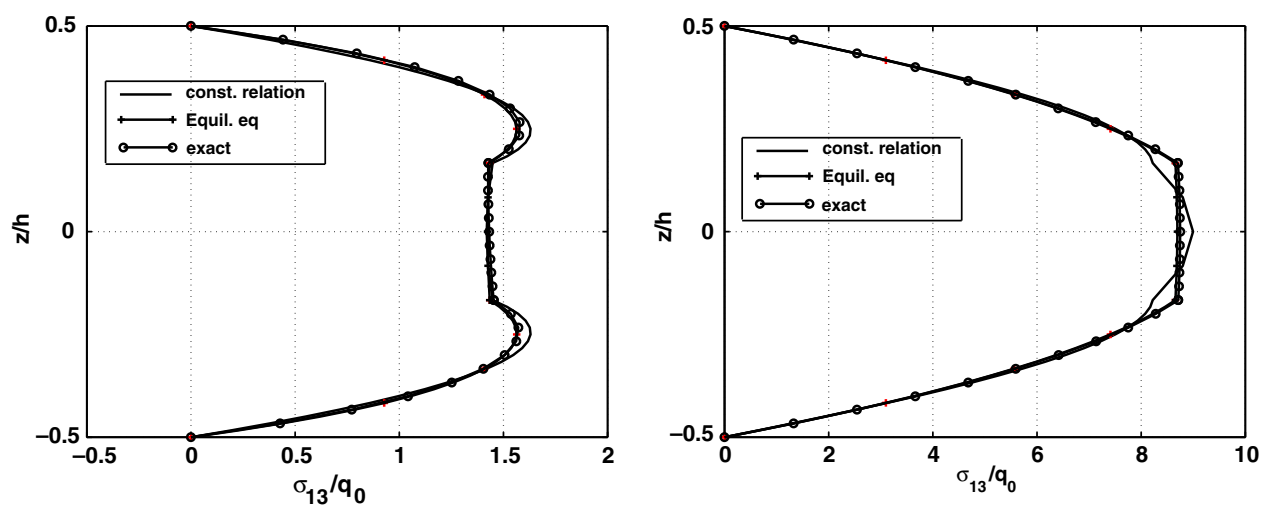

Fig. 10. Distribution of $\bar{\sigma}_{13}$ along the thickness $-S=4$ (left) and $S=20$ (right) - three layers $\left(0^{\circ} / 90^{\circ} / 0^{\circ}\right)$-SinRef-c.
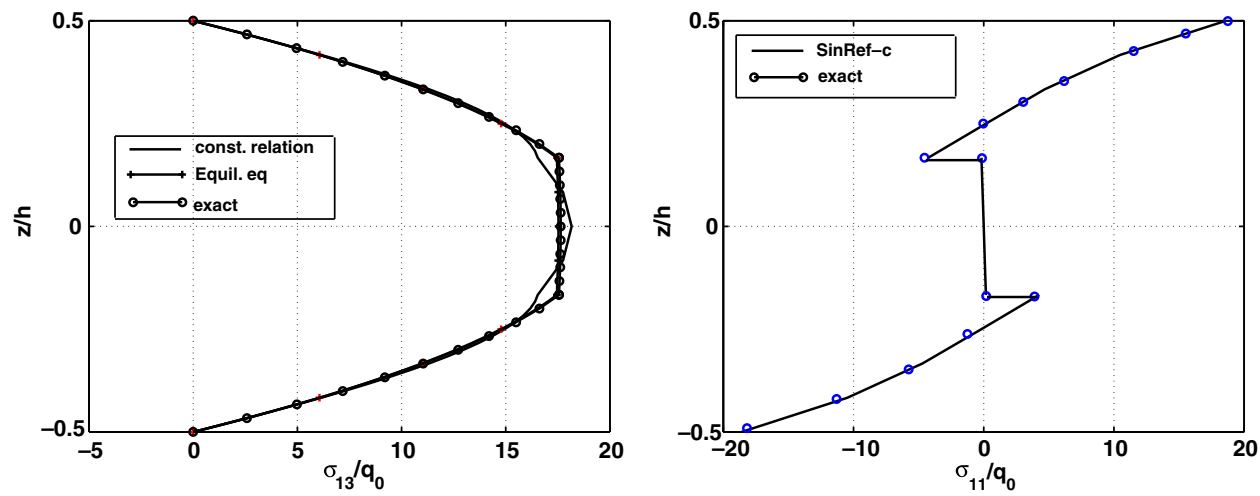

Fig. 11. Distribution of $\bar{\sigma}_{13} S=40$ (left) and $\bar{\sigma}_{11} S=4$ (right) along the thickness - three layers $\left(0^{\circ} / 90^{\circ} / 0^{\circ}\right)$ - SinRef-c.
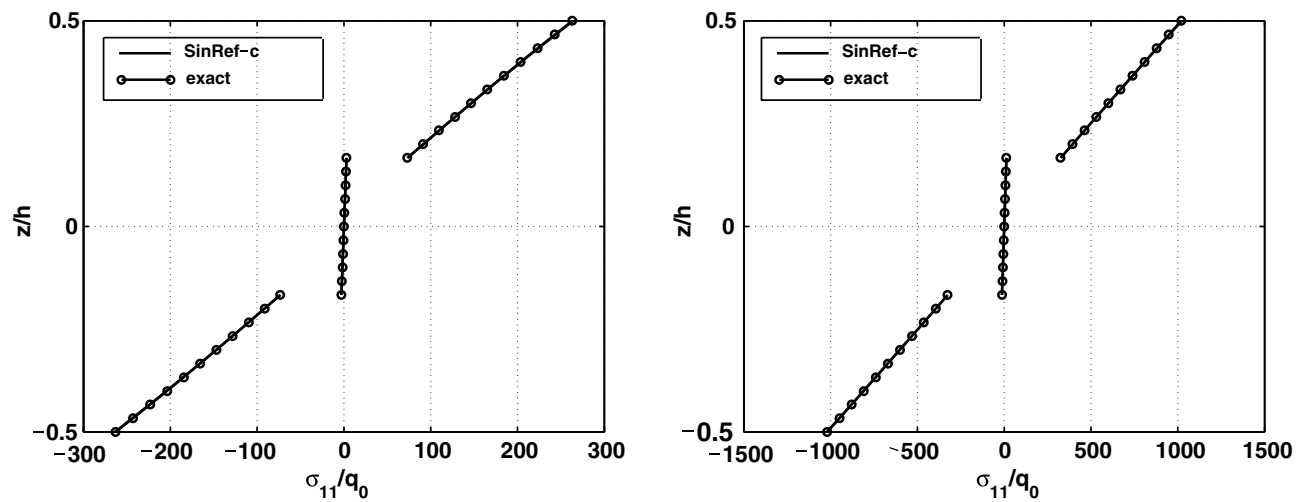

Fig. 12. Distribution of $\bar{\sigma}_{11}$ along the thickness $-S=20$ (left) and $S=40$ (right) - three layers $\left(0^{\circ} / 90^{\circ} / 0^{\circ}\right)$-SinRef-c.
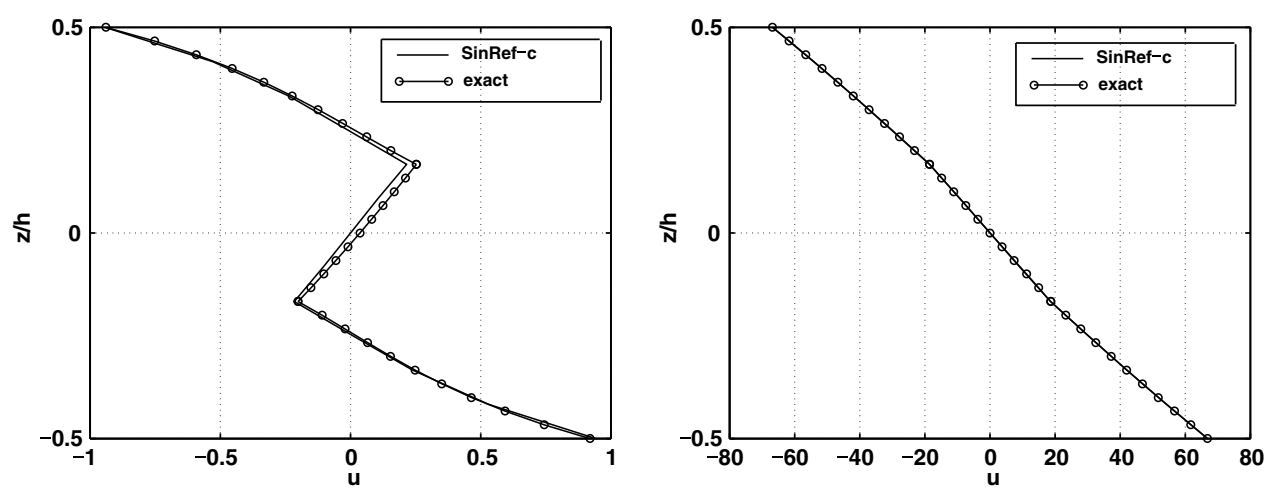

Fig. 13. Distribution of $\bar{u}$ along the thickness $-S=4$ (left) and $S=20$ (right) - three layers $\left(0^{\circ} / 90^{\circ} / 0^{\circ}\right)$-SinRef-c. 


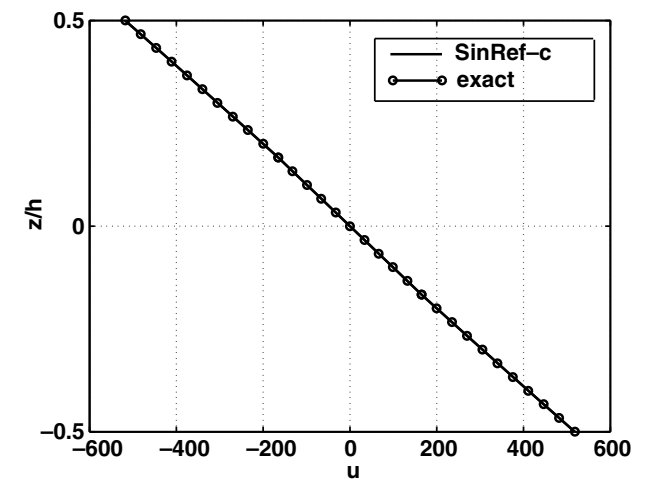

Fig. 14. Distribution of $\bar{u}$ along the thickness $-S=40-$ three layers $\left(0^{\circ} / 90^{\circ} / 0^{\circ}\right)$-SinRef-c.

Table 9

Deflection and stresses for the viscoelastic sandwich beam

\begin{tabular}{|c|c|c|c|c|}
\hline & Sin & Sin-c & SinRef-c & $\begin{array}{l}\text { ANSYS } \\
\text { (2D) }\end{array}$ \\
\hline \multicolumn{5}{|l|}{ Case 1} \\
\hline$v_{3}(L / 2,0)$ & $-4.72 \mathrm{e}-5$ & $-7.31 \mathrm{e}-5$ & $-7.25 e-5$ & $-7.32 \mathrm{e}-5$ \\
\hline$\sigma_{13}(L / 4,0)$ & $-0.195 \mathrm{e} 2$ & $-0.676 \mathrm{e} 4$ & $-0.686 \mathrm{e} 4$ & $-6.79 \mathrm{e} 3$ \\
\hline $\begin{array}{c}\sigma_{13}(L / 4,0) \\
\text { EqEqu }\end{array}$ & $-0.692 \mathrm{e} 4$ & $-0.682 \mathrm{e} 4$ & $-0.682 \mathrm{e} 4$ & \\
\hline$\sigma_{11}(L / 4, e / 2)$ & $-0.389 \mathrm{e} 6$ & $-0.397 \mathrm{e} 6$ & $-0.397 \mathrm{e} 6$ & $-3.98 \mathrm{e} 5$ \\
\hline \multicolumn{5}{|l|}{ Case 2} \\
\hline$v_{3}(L / 2,0)$ & $-0.472 \mathrm{e}-4$ & $-0.472 \mathrm{e}-4$ & $-0.472 \mathrm{e}-4$ & $-0.472 \mathrm{e}-4$ \\
\hline$\sigma_{13}(L / 4,0)$ direct & $-0.701 \mathrm{e} 4$ & $-0.701 \mathrm{e} 4$ & $-0.721 \mathrm{e} 4$ & $-0.700 \mathrm{e} 4$ \\
\hline $\begin{array}{r}\sigma_{13}(L / 4,0) \\
\text { EqEqu }\end{array}$ & $-0.698 \mathrm{e} 4$ & $-0.698 \mathrm{e} 4$ & $-0.698 \mathrm{e} 4$ & \\
\hline$\sigma_{11}(L / 4, h / 2)$ & $-0.388 \mathrm{e} 6$ & $-0.388 \mathrm{e} 6$ & $-0.388 \mathrm{e} 6$ & $-0.388 \mathrm{e} 6$ \\
\hline
\end{tabular}

\subsubsection{Symmetric laminated composite [44,45]}

The example is issued from $[44,45]$. It deals with a symmetric laminated composite with the following characteristics:

geometry: the beam studied has a length of $L=6.35 \mathrm{~m}$, and a thickness $h=0.2794 \mathrm{~m}$ (thin $S \approx 22.7$ ), and $h=2.794 \mathrm{~m}$ (thick $S \approx 2.2$ ). It possesses three layers at $\left(90^{\circ} / 0^{\circ} / 90^{\circ}\right)$, with thickness $(0.25 \mathrm{~h} /$ $0.5 \mathrm{~h} / 0.25 \mathrm{~h}$ ).

boundary conditions: simply supported beam.

material properties: the material used is boron epoxy which has the following mechanical properties:
$E_{11}=241.5 \mathrm{GPa}, \quad E_{22}=E_{33}=18.89 \mathrm{GPa}$,

$G_{12}=G_{13}=5.18 \quad \mathrm{GPa} \quad G_{23}=3.45 \mathrm{GPa}$,

$v_{12}=v_{13}=0.24, \quad v_{23}=0.25$

$\rho=2015 \mathrm{~kg} / \mathrm{m}^{3}$.

mesh: $N=8$.

results: the mode shapes are precised as: bend, sh, $t / c$ for bending, shear and axial mode respectively.

Tables 11 and 12 present numerical values of frequencies for the thin and thick beam. These results show the excellent agreement with reference values for eight and seven natural frequencies. Results of the SinRef-c model are better than these of the Sin and Sin-c models, especially for the thick beam. The maximal \% error is 2.9 , whereas the two others have an error of $17 \%$ and $14 \%$ respectively. It should be noted that the values of the natural frequencies are always overestimated.

\subsubsection{Free vibration of symmetric and anti-symmetric lay-up [31]}

In this section, two stacking sequences of laminated composite are considered:

geometry: composite cross-ply beam $\left(0^{\circ} / 90^{\circ} / 0^{\circ}\right),\left(0^{\circ} / 90^{\circ}\right)$ and length to thickness ratio $S=5, S=10$, $S=20$.

boundary conditions: free vibration of a simply supported beam.

material properties: same material properties as in Section 3.2.1.

results: the results are presented under a non-dimensional natural frequency as follows:

$\bar{\omega}=\omega L S\left(\rho / Y_{0}\right)^{1 / 2}$

with $Y_{0}=10.3 \mathrm{GPa}, \rho=1578 \mathrm{~kg} / \mathrm{m}^{3}$. They are compared with exact $2 \mathrm{D}$ reference solution from [31].The shape modes for the thick symmetric beam are given in Fig. 16.

It can be noticed that the natural frequencies given in Table 13 for the symmetric lay-up $\left(0^{\circ} / 90^{\circ} / 0^{\circ}\right)$ are in excellent agreement with the reference solution. The errors are less than $0.6 \%$, excepted for extensional mode frequencies $(2 \%)$. The SinRef-c model improves results issued from the Sin and Sin-c models.

Table 10

Mesh convergence study for the SinRef-c model-natural frequencies - three layers $\left(0^{\circ} / 90^{\circ} / 0^{\circ}\right)-S=10$

\begin{tabular}{|c|c|c|c|c|c|c|}
\hline \multirow[b]{2}{*}{$N$} & \multicolumn{6}{|c|}{ Frequencies $(\mathrm{Hz})$} \\
\hline & 2 & Error $(\%)$ & 4 & Error $(\%)$ & 8 & Error $(\%)$ \\
\hline & 38.17 & 0.4 & 38.07 & 0.1 & 38.06 & 0.1 \\
\hline & 211.53 & 12 & 190.29 & 0.7 & 189.21 & 0.1 \\
\hline & - & & 276.24 & 2.6 & 269.40 & 0.1 \\
\hline & 345.29 & 1.7 & 366.06 & 4.1 & 351.78 & 0.1 \\
\hline & 391.44 & 2.6 & 390.07 & 2.2 & 389.98 & 2.2 \\
\hline
\end{tabular}




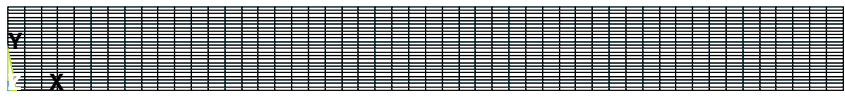

Fig. 15. Mesh with 1275 dofs (ANSYS).

As for the anti-symmetric lay-up $\left(0^{\circ} / 90^{\circ}\right)$, the errors given in Table 14 vary from $0 . \%$ to $1.8 \%$ for the SinRef-c model. The improvement is really significant compared with the two other models, especially for the very thick beam.

\subsubsection{Free vibration of sandwich beam [31]}

The last example concerns a sandwich beam with the following characteristics:

geometry: The 3-layer sandwich beam has graphite-epoxy faces and a soft core with thickness $0.1 \mathrm{~h} / 0.8 \mathrm{~h} /$ $0.1 \mathrm{~h}$ and length to thickness ratio $S=5$, $S=10, S=20$.

boundary conditions: free vibration of a simply supported beam.

material properties: Face: $\quad E_{11}=131.1 \mathrm{GPa}, \quad E_{22}=E_{33}$ $=6.9 \mathrm{GPa}$ $G_{12}=3.588 \mathrm{GPa}, \quad G_{13}=3.088 \mathrm{GPa}$, $G_{23}=2.3322 \mathrm{GPa}$,

$v_{12}=v_{13}=0.32, \quad v_{23}=0.49$, $\rho_{\mathrm{f}}=1000 \mathrm{~kg} / \mathrm{m}^{3}$.

Core: $\quad E_{11}=0.2208 \mathrm{MPa}, \quad E_{22}=$ $0.2001 \mathrm{MPa}, E_{33}=2760 \mathrm{MPa}$

$G_{12}=16.56 \mathrm{MPa}, G_{13}=545.1 \mathrm{MPa}$, $G_{23}=455.4 \mathrm{MPa}$
1

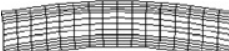

4

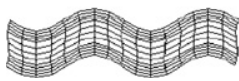

Fig. 16. Shape modes for the symmetric beam $\left(0^{\circ} / 90^{\circ} / 0^{\circ}\right)-S=$ 5-SinRef-c.

$$
\begin{aligned}
& v_{12}=0.99, \quad v_{13}=0.00003, \\
& v_{23}=0.00003, \rho_{\mathrm{c}}=70 \mathrm{~kg} / \mathrm{m}^{3} .
\end{aligned}
$$

results: results are presented under a non-dimensional natural frequency as follows:

$\bar{\omega}=\omega L S\left(\rho_{\mathrm{f}} / Y_{0}\right)^{1 / 2}$

with $Y_{0}=6.9 \mathrm{GPa}$.

As for the sandwich beam, the Table 15 shows that the refined sinus model yields accurate results in all cases. The $\%$ error is about 3.

The three models are able to estimate accurately the natural frequencies of a sandwich beam. In our case, the Sin-c model gives the best results, except for the last modes of the thick case where the SinRef-c seems to be more precise (the error about the eighth mode is significant).

All these different examples prove the efficiency of the refined sinus model for free vibration analysis. Few elements are needed to obtain good results. Moreover, numerical results of laminated composite and sandwich beam for

Table 11

\begin{tabular}{|c|}
\hline Ansys \\
\hline 14.93 \\
\hline 57.67 \\
\hline 204.50 \\
\hline 297.23 \\
\hline 397.28 \\
\hline
\end{tabular}

Natural frequencies - three layers $\left(90^{\circ} / 0^{\circ} / 90^{\circ}\right)-S \approx 22.7$

Table 12

\begin{tabular}{|c|c|c|c|c|c|c|}
\hline $\operatorname{Sin}$ & Error $(\%)$ & Sin-c & Error $(\%)$ & SinRef-c & Error $(\%)$ & Ansys \\
\hline 82.81 & 0.7 & 83.66 & 1. & 82.78 & 0.7 & 82.17 \\
\hline 195.62 & 0.2 & 195.67 & 0.3 & 195.83 & 0.3 & 195.22 \\
\hline 319.36 & 2.9 & 313.36 & 1. & 311.73 & 0.5 & 310.07 \\
\hline 460.18 & 8.4 & 442.07 & 4.1 & 428.96 & 1. & 424.311 \\
\hline 515.41 & 17.4 & 501.47 & 14.2 & 451.63 & 2.9 & 438.81 \\
\hline
\end{tabular}

Natural frequencies - three layers $\left(90^{\circ} / 0^{\circ} / 90^{\circ}\right)-S \approx 2.2$ 
Table 13

Natural frequencies $-\left(0^{\circ} / 90^{\circ} / 0^{\circ}\right)$

\begin{tabular}{|c|c|c|c|c|c|c|c|c|c|}
\hline \multirow[t]{2}{*}{$S$} & \multicolumn{9}{|c|}{ Natural frequencies $\bar{\omega}$} \\
\hline & & Sin & Error $(\%)$ & Sin-c & Error $(\%)$ & SinRef-c & Error $(\%)$ & Ansys & Exact 2D [31] \\
\hline \multirow[t]{7}{*}{5} & Bend & 6.94 & 1.9 & 6.82 & 0.2 & 6.81 & 0.2 & 6.806 & 6.806 \\
\hline & Bend & 16.80 & 1.6 & 16.79 & 1.6 & 16.54 & 0.1 & 16.52 & 16.515 \\
\hline & Bend & 27.17 & 1.6 & 28.07 & 5. & 26.73 & 0.04 & 26.72 & 26.688 \\
\hline & Bend & 38.51 & 3.1 & 41.35 & 10.7 & 37.32 & 0.02 & 37.33 & 37.255 \\
\hline & $\mathrm{sh}$ & 46.76 & 6.7 & 43.93 & 0.3 & 43.80 & 0.01 & 43.79 & \\
\hline & Bend & 47.86 & 0.6 & 47.86 & 0.6 & 48.18 & 0.4 & 48.17 & 48.035 \\
\hline & Bend & 51.24 & 13.3 & 57.13 & 3.3 & 59.26 & 0.2 & 59.11 & 58.876 \\
\hline \multirow[t]{7}{*}{10} & Bend & 9.44 & 1. & 9.34 & 0. & 9.36 & 0.1 & 9.34 & 9.343 \\
\hline & Bend & 27.76 & 1.9 & 27.29 & 0.1 & 27.25 & 0.1 & 27.24 & 27.224 \\
\hline & Bend & 47.36 & 1.9 & 46.78 & 0.6 & 46.53 & 0.1 & 46.47 & 46.416 \\
\hline & Bend & 67.29 & 1.6 & 67.23 & 1.6 & 66.25 & 0.1 & 66.19 & 66.058 \\
\hline & Bend & 87.77 & 1.5 & 89.13 & 3.1 & 86.51 & 0.1 & 86.43 & 86.169 \\
\hline & $\mathrm{t} / \mathrm{c}$ & 95.73 & 2. & 95.73 & 2. & 95.90 & 2.2 & 93.78 & \\
\hline & Bend & - & & 113.04 & 5.4 & 107.38 & 0.1 & 107.20 & 106.75 \\
\hline \multirow[t]{7}{*}{20} & Bend & 10.67 & 0.2 & 10.64 & 0. & 10.65 & 0.1 & 10.64 & 10.64 \\
\hline & Bend & 37.78 & 1. & 37.39 & 0. & 37.45 & 0.1 & 37.40 & 37.374 \\
\hline & Bend & 72.98 & 1.5 & 71.87 & 0. & 71.94 & 0.1 & 71.85 & 71.744 \\
\hline & Bend & 111.23 & 1.9 & 109.35 & 0.1 & 109.30 & 0.1 & 109.15 & 108.89 \\
\hline & Bend & 150.57 & 2. & 148.21 & 0.4 & 147.83 & 0.2 & 147.54 & 147.04 \\
\hline & Bend & 190.54 & 2.1 & 188.26 & 0.9 & 187.19 & 0.3 & 186.53 & 185.68 \\
\hline & $\mathrm{t} / \mathrm{c}$ & 191.47 & 0.4 & 191.47 & 0.4 & 191.81 & 0.6 & 190.52 & \\
\hline
\end{tabular}

Table 14

Natural frequencies-anti-symmetric lay-up $\left(0^{\circ} / 90^{\circ}\right)$

\begin{tabular}{|c|c|c|c|c|c|c|c|c|}
\hline \multirow[t]{2}{*}{$S$} & \multicolumn{8}{|c|}{ Natural frequencies $\bar{\omega}$} \\
\hline & & $\operatorname{Sin}$ & Error $(\%)$ & Sin-c & Error $(\%)$ & SinRef-c & Error $(\%)$ & Ansys \\
\hline \multirow[t]{6}{*}{5} & Bend & 4.83 & 1 & 4.87 & 2 & 4.78 & 0.2 & 4.77 \\
\hline & Bend & 15.19 & 4 & 15.60 & 6 & 14.71 & 0.6 & 14.61 \\
\hline & Bend & 27.30 & 7 & 28.64 & 12 & 25.87 & 1.8 & 25.40 \\
\hline & tc & 38.12 & 7 & 36.39 & 3 & 35.56 & 0.4 & 35.42 \\
\hline & Bend & 40.29 & 12 & 43.09 & 19 & 37.42 & 4 & 36.02 \\
\hline & sh & 54.15 & 11 & 50.29 & 3 & 48.52 & 0. & 48.52 \\
\hline \multirow[t]{6}{*}{10} & Bend & 5.30 & 0.3 & 5.32 & 0.5 & 5.29 & 0.1 & 5.29 \\
\hline & Bend & 19.33 & 1 & 19.49 & 2 & 19.14 & 0.1 & 19.12 \\
\hline & Bend & 38.67 & 2 & 39.33 & 4 & 37.87 & 0.2 & 37.77 \\
\hline & Bend & 60.91 & 4 & 62.57 & 7 & 58.97 & 0.6 & 58.60 \\
\hline & Bend & 84.87 & 6 & 88.13 & 9 & 81.26 & 1 & 80.22 \\
\hline & tc & 90.06 & 2 & 88.92 & 0.5 & 88.65 & 0.2 & 88.44 \\
\hline \multirow[t]{7}{*}{20} & Bend & 5.45 & $<0.1$ & 5.46 & 0.1 & 5.45 & 0.1 & 5.45 \\
\hline & Bend & 21.23 & 0.3 & 21.28 & 0.4 & 21.20 & 0.1 & 21.18 \\
\hline & Bend & 45.86 & 0.7 & 46.08 & 1 & 45.62 & 0.1 & 45.55 \\
\hline & Bend & 77.58 & 1 & 78.23 & 2 & 76.81 & 0.3 & 76.59 \\
\hline & Bend & 114.86 & 2 & 116.31 & 3 & 113.11 & 0.6 & 112.40 \\
\hline & Bend & 156.58 & 3 & 159.32 & 5 & 153.29 & 1 & 151.48 \\
\hline & tc & 188.63 & 0.4 & 188.09 & 0.1 & 188.26 & 0.2 & 187.89 \\
\hline
\end{tabular}

various aspect ratios show the capability of this model. It can also be noticed that the refined sinus model overestimates frequencies compared to the reference solution.

\section{Conclusion}

In this article, a new numerical model, denoted SinRef-c, has been presented and evaluated through different benchmarks. This new FE has been described in the framework of hierarchical sinus family. It is a three-node multilayered (sandwich and laminated) beam finite element for static and dynamic analysis. Based on sinus equivalent single layer model, a third order kinematic per layer is added, improving the bending description for thick beams. There is no need for transverse shear correction factors and all the interface and boundary conditions are exactly satisfied. So, this approach has a strong physical meaning. Finally, the classical three unknown functions (two displacements, one rotation) are 


\begin{tabular}{|c|c|c|c|c|c|c|c|c|c|}
\hline \multirow[t]{2}{*}{$S$} & \multicolumn{9}{|c|}{ Natural frequencies $\bar{\omega}$} \\
\hline & & Sin & Error $(\%)$ & Sin-c & Error $(\%)$ & SinRef-c & Error $(\%)$ & Ansys & Exact 2D [31] \\
\hline \multirow[t]{5}{*}{5} & Bend & 8.09 & 3.4 & 7.85 & 0.3 & 8.04 & 2.7 & 7.82 & 7.82 \\
\hline & Bend & 17.96 & 3.9 & 17.43 & 0.8 & 17.86 & 3.3 & 17.28 & 17.27 \\
\hline & sh & 34.66 & 3.7 & 33.42 & 0. & 34.22 & 2.4 & 33.40 & \\
\hline & Bend & 38.62 & 4.3 & 38.27 & 3.4 & 38.35 & 3.6 & 37.01 & 36.93 \\
\hline & Bend & 50.06 & 5.2 & 50.32 & 5.8 & 49.31 & 3.6 & 47.55 & 47.39 \\
\hline \multirow[t]{5}{*}{10} & Bend & 12.49 & 2.1 & 12.25 & 0.1 & 12.45 & 1.7 & 12.23 & 12.23 \\
\hline & Bend & 32.37 & 3.4 & 31.41 & 0.3 & 32.16 & 2.7 & 31.30 & 31.29 \\
\hline & Bend & 52.17 & 3.8 & 50.53 & 0.5 & 51.82 & 3.1 & 50.26 & 50.21 \\
\hline & Bend & 71.90 & 3.8 & 69.77 & 0.8 & 71.48 & 3.2 & 69.21 & 68.09 \\
\hline & Bend & 91.88 & 3.9 & 89.52 & 1.2 & 91.43 & 3.4 & 88.41 & 88.18 \\
\hline & Bend & 89.53 & 2.8 & 87.18 & 0.2 & 89.03 & 2.3 & 87.01 & 86.90 \\
\hline & Bend & 169.56 & 3.6 & 164.26 & 0.4 & 168.41 & 2.9 & 163.58 & 163.12 \\
\hline & Bend & 209.45 & 3.8 & 202.88 & 0.6 & 208.08 & 3.1 & 201.64 & 200.87 \\
\hline & $\mathrm{t} / \mathrm{c}$ & 242.08 & 0.2 & 242.06 & 0.2 & 242.73 & 0.4 & 241.61 & \\
\hline
\end{tabular}

used and only one more function is needed in this new model. In fact, this finite element is simple and efficient for a low cost, compared to layerwise approach or plane elasticity model in commercial softwares.

Several numerical evaluations have proved that this model has very good properties in the field of finite elements. Convergence velocity is high for static and vibration analysis and accurate results are obtained. Compared to the sinus model (with and without continuity), this new finite element improves numerical results. The thick $(S=4)$ two-layer beam is the best example showing the efficiency of SinRefc. Moreover, we can stress the emphasis on the good distribution of the stresses across the thickness even if they are directly computed from the constitutive relation. Moreover, maximum values of the transverse shear stress are calculated precisely. Concerning the free vibration analysis, natural frequencies are very well predicted.

In all these tests, the necessity to impose the continuity conditions of the transverse shear stress between the layers is obvious. In thick case tests $(S=4)$, refinement of the bending part using only one more unknown function is sufficient to achieve accurate results, considering the transverse normal stress at zero. Multiphysics problems are now investigated using this new model, and special attention is pointed towards the transverse normal stress effect.

\section{Appendix A. Sinus model with continuity conditions}

\section{A.1. Displacement field}

The beam displacement field in the $\left(0, x_{1}, z\right)$ plane is defined as follows:

$$
\left\{\begin{aligned}
u_{1}\left(x_{1}, z\right)= & u\left(x_{1}\right)+z v\left(x_{1}\right)+f(z) u_{2}\left(x_{1}\right)+g(z) v_{2}\left(x_{1}\right) \\
& +\sum_{i=1}^{(\mathrm{NC})-1} u_{i}^{c}\left(x_{1}\right)\left(z-z_{i+1}\right) H\left(z-z_{i+1}\right) \\
u_{3}\left(x_{1}, z\right)= & w\left(x_{1}\right)
\end{aligned}\right.
$$

in which $u\left(x_{1}\right), v\left(x_{1}\right), u_{2}\left(x_{1}\right), v_{2}\left(x_{1}\right), u_{i}^{c}\left(x_{1}\right), w\left(x_{1}\right)$ are the unknown functions. $u_{i}^{c}\left(x_{1}\right)$ is used in order to ensure the continuity conditions on the interface layers.

$\mathrm{H}$ is the Heaviside function, $f(z)$ and $g(z)$ are trigonometric functions defined by

$$
\left\{\begin{array} { l } 
{ f ( z ) = \frac { h } { \pi } \operatorname { s i n } ( \frac { \pi z } { h } ) } \\
{ f ^ { \prime } ( z ) = \operatorname { c o s } ( \frac { \pi z } { h } ) }
\end{array} \quad \left\{\begin{array}{l}
g(z)=\frac{h}{\pi} \cos \left(\frac{\pi z}{h}\right) \\
g^{\prime}(z)=-\sin \left(\frac{\pi z}{h}\right)
\end{array}\right.\right.
$$

Finally, the transverse shear strain component is given by

$$
\begin{aligned}
\gamma_{13}\left(x_{1}, z\right)= & v\left(x_{1}\right)+w^{\prime}\left(x_{1}\right)+f^{\prime}(z) u_{2}\left(x_{1}\right)+g^{\prime}(z) v_{2}\left(x_{1}\right) \\
& +\sum_{i=1}^{(\mathrm{NC})-1} u_{i}^{c}\left(x_{1}\right) H\left(z-z_{i+1}\right)
\end{aligned}
$$

\section{A.2. Boundary conditions on the top and bottom surfaces}

- bottom surface $z_{1}=-\frac{h}{2}$; from Eq. (A.2), the following relation is obtained:

$$
\begin{aligned}
\sigma_{13}^{(1)}\left(z_{1}\right)=0 & \Longleftrightarrow G^{(1)}\left(v\left(x_{1}\right)+w^{\prime}\left(x_{1}\right)+v_{2}\left(x_{1}\right)\right)=0 \\
& \Longleftrightarrow v\left(x_{1}\right)+w^{\prime}\left(x_{1}\right)=-v_{2}\left(x_{1}\right)
\end{aligned}
$$

- top surface $z_{\mathrm{NC}+1}=\frac{h}{2}$; in the same way, we have: 


$$
\begin{aligned}
& \sigma_{13}^{(\mathrm{NC})}\left(z=z_{\mathrm{NC}+1}\right)=0 \\
& \left.\Longleftrightarrow G^{(\mathrm{NC})} v\left(x_{1}\right)+w^{\prime}\left(x_{1}\right)-v_{2}\left(x_{1}\right)+\sum_{i=1}^{(\mathrm{NC})-1} u_{i}^{c}\left(x_{1}\right)\right)=0 \\
& \Longleftrightarrow \sum_{i=1}^{(\mathrm{NC})-1} u_{i}^{c}\left(x_{1}\right)=2 v_{2}\left(x_{1}\right)
\end{aligned}
$$

Then, the following relations are deduced:

$$
\begin{aligned}
& v\left(x_{1}\right)=-w^{\prime}\left(x_{1}\right)-\frac{1}{2} \sum_{i=1}^{(\mathrm{NC})-1} u_{i}^{c}\left(x_{1}\right) \\
& v_{2}\left(x_{1}\right)=\frac{1}{2} \sum_{i=1}^{(\mathrm{NC})-1} u_{i}^{c}\left(x_{1}\right)
\end{aligned}
$$

Therefore, introducing Eq. (A.5) in Eq. (A.1), new displacement field can be written as below:

$$
\left\{\begin{aligned}
u_{1}\left(x_{1}, z\right)= & u\left(x_{1}\right)-z w^{\prime}\left(x_{1}\right)+f(z) u_{2}\left(x_{1}\right) \\
& +\sum_{i=1}^{(\mathrm{NC})-1} u_{i}^{c}\left(x_{1}\right)\left\{-\frac{1}{2} z+\frac{1}{2} g(z)+\left(z-z_{i+1}\right) H\left(z-z_{i+1}\right)\right\} \\
u_{3}\left(x_{1}, z\right)= & w\left(x_{1}\right)
\end{aligned}\right.
$$

Unknown functions $u_{i}^{c}\left(x_{1}\right)$ are now used to ensure the continuity conditions at each layer interface.

\section{A.3. Continuity conditions for the transverse shear stress}

From Eq. (A.6), the transverse shear strain is

$$
\begin{aligned}
\gamma_{13}\left(x_{1}, z\right)= & f^{\prime}(z) u_{2}\left(x_{1}\right) \\
& +\sum_{i=1}^{(\mathrm{NC})-1} u_{i}^{c}\left(x_{1}\right)\left(-\frac{1}{2}+\frac{1}{2} g^{\prime}(z)\right) \\
& +\sum_{i=1}^{(\mathrm{NC})-1} u_{i}^{c}\left(x_{1}\right) H\left(z-z_{i+1}\right)
\end{aligned}
$$

Therefore, continuity condition is ensured writing:

$\sigma_{13}^{(k)}\left(z=z_{k+1}\right)=\sigma_{13}^{(k+1)}\left(z=z_{k+1}\right)$

- layer $(k)$ :

$\sigma_{13}^{(k)}\left(z=z_{k+1}\right)$

$$
\left.=G^{(k)} f^{\prime}\left(z_{k+1}\right) u_{2}\left(x_{1}\right)+\frac{1}{2} \sum_{i=1}^{(\mathrm{NC})-1} u_{i}^{c}\left(x_{1}\right)\left(g^{\prime}\left(z_{k+1}\right)-1\right)+\sum_{i=1}^{k-1} u_{i}^{c}\left(x_{1}\right)\right)
$$

- layer $(k+1)$;

$$
\begin{aligned}
\sigma_{13}^{(k+1)}\left(z=z_{k+1}\right)= & G^{(k+1)} f^{\prime}\left(z_{k+1}\right) u_{2}\left(x_{1}\right)+\frac{1}{2} \sum_{i=1}^{(\mathrm{NC})-1} u_{i}^{c}\left(x_{1}\right) \\
& \left.\times\left(g \prime\left(z_{k+1}\right)-1\right)+\sum_{i=1}^{k-1} u_{i}^{c}\left(x_{1}\right)+u_{k}^{c}\left(x_{1}\right)\right)
\end{aligned}
$$

For $k \in\{1, \mathrm{NC}-1\}$, continuity conditions for the transverse shear stress is

$$
\begin{aligned}
& G^{(k)} f^{\prime}\left(z_{k+1}\right) u_{2}\left(x_{1}\right)+\frac{1}{2} \sum_{i=1}^{(\mathrm{NC})-1} u_{i}^{c}\left(x_{1}\right)\left(g^{\prime}\left(z_{k+1}\right)-1\right) \\
& \left.+\sum_{i=1}^{k-1} u_{i}^{c}\left(x_{1}\right)\right)=G^{(k+1)} \\
& f^{\prime}\left(z_{k+1}\right) u_{2}\left(x_{1}\right)+\frac{1}{2} \sum_{i=1}^{(\mathrm{NC})-1} u_{i}^{c}\left(x_{1}\right)\left(g^{\prime}\left(z_{k+1}\right)-1\right) \\
& \left.+\sum_{i=1}^{k-1} u_{i}^{c}\left(x_{1}\right)+u_{k}^{c}\left(x_{1}\right)\right)
\end{aligned}
$$

which can be written under the following form:

$$
\begin{aligned}
\left(G^{(k)}-G^{(k+1)}\right) f^{\prime}\left(z_{k+1}\right) u_{2}= & G^{(k+1)} u_{k}^{c}\left(x_{1}\right)-\left(G^{(k+1)}-G^{(k)}\right) \\
& \left.\times \frac{1}{2} \sum_{i=1}^{(\mathrm{NC})-1} u_{i}^{c}\left(x_{1}\right)\left(g^{\prime}\left(z_{k+1}\right)-1\right)+\sum_{i=1}^{k-1} u_{i}^{c}\left(x_{1}\right)\right)
\end{aligned}
$$

Finally, a system of $\mathrm{NC}-1$ equations is obtained for the $\mathrm{NC}-1$ unknown functions $u_{i}^{c}\left(x_{1}\right)$. This system is denoted: $[A][U]=[B] u_{2}$

where $[U]^{t}=\left[u_{1}^{c} u_{2}^{c} \ldots \ldots u_{\mathrm{NC}-1}^{c}\right]$ and the coefficients $A_{k l}$ of $[A]$ for $k \in\{1, \mathrm{NC}-1\}$ are:

$$
\begin{aligned}
& l<k: A_{k l}=\left(G^{(k+1)}-G^{(k)}\right)\left(g^{\prime}\left(z_{k+1}\right)+1\right) \\
& l=k: A_{k l}=G^{k}+G^{(k+1)}+\left(G^{(k+1)}-G^{(k)}\right) g^{\prime}\left(z_{k+1}\right) \\
& l>k: A_{k l}=\left(G^{(k+1)}-G^{(k)}\right)\left(g^{\prime}\left(z_{k+1}\right)-1\right) \\
& \text { while second member }[B] \text { is defined by coefficient: }
\end{aligned}
$$

$B_{k}=2\left(G^{(k)}-G^{(k+1)}\right) f^{\prime}\left(z_{k+1}\right)$

Finally, the solution of this system gives relations as $u_{i}^{c}\left(x_{1}\right)=\alpha_{i} u_{2}\left(x_{1}\right)$ where coefficients $\alpha_{i}$ are expressed from $\left(G^{(k)}\right)_{k=1, \mathrm{NC}} ;\left(z_{k+1} ; g^{\prime}\left(z_{k+1}\right) ; f^{\prime}\left(z_{k+1}\right)\right)_{k=1, \mathrm{NC}-1}$.

\section{A.4. Final displacement field}

The final displacement field takes the following form

$$
\left\{\begin{aligned}
u_{1}\left(x_{1}, z\right)= & u\left(x_{1}\right)-z w^{\prime}\left(x_{1}\right)+u_{2}\left(x_{1}\right)\{f(z)+ \\
& \left.\sum_{i=1}^{(\mathrm{NC})-1} \alpha_{i}\left(-\frac{1}{2} z+\frac{1}{2} g(z)+\left(z-z_{i+1}\right) H\left(z-z_{i+1}\right)\right)\right\} \\
u_{3}\left(x_{1}, z\right)= & w\left(x_{1}\right)
\end{aligned}\right.
$$

Remark. for $\mathrm{NC}=1$, the sinus model is recovered with $u_{2}\left(x_{1}\right)=\omega_{3}\left(x_{1}\right)+w^{\prime}\left(x_{1}\right)$. 


\section{References}

[1] Tanigawa Y, Murakami H, Ootao Y. Transient thermal stress analysis of a laminated composite beam. J Thermal Stress 1989; 12:25-39.

[2] Lee C-Y, Liu D, Lu X. Static and vibration analysis of laminated composite beams with an interlaminar shear stress continuity theory. Int J Numer Methods Eng 1992;33:409-24.

[3] Soldatos KP, Elishakoff I. A transverse shear and normal deformable orthotropic beam theory. J Sound Vibr 1992;155(3):528-33.

[4] Reddy JN. A simple higher-order theory for laminated composite plates. J Appl Mech ASME 1984;51(4):745-52.

[5] Marur SR, Kant T. On the performance of higher order theories for transient dynamic analysis of sandwich and composite beams. Comput Struct 1997;65(5):741-59.

[6] Liu S, Soldatos KP. On the prediction improvement of transverse stress distributions in cross-ply lamionated beams: advanced versus conventional beam modelling. Int J Mech Sci 2002;44:287-304.

[7] Murthy MVVS, Roy Mahapatra D, Badarinarayana K, Gopalakrishnan S. A refined higher order finite element for asymmetric composite beams. Compos Struct 2005;67(1):27-35.

[8] Subramanian P. Dynamic analysis of laminated composite beams using higher order theories and finite elements. Compos Struct 2006;73:342-53.

[9] Vinayak RU, Prathap G, Naganarayana BP. Beam elements based on a higher order theory - i. Formulation and analysis of performance. Comput Struct 1996;58(4):775-89.

[10] Matsunaga H. Interlaminar stress analysis of laminated composite beams according to global higher-order deformation theories. Comput Struct 2002;55(1):105-14.

[11] Noor AK, Burton WS. Stress and free vibration analysis of multilayered composite plates. Comput Struct 1989;11(3):183-204.

[12] Carrera E. Layer-wise mixed models for accurate vibrations analysis of multilayered plates. J Appl Mech ASME 1998;65:820-8.

[13] Reddy JN. On refined computational models of composite laminates. Int J Numer Methods Eng 1989;27:361-82.

[14] Karger L, Wetzel A, Rolfes R, Rohwer K. A three-layered sandwich element with improved transverse shear stiffness and stresses based on fsdt. Comput Struct 2006;84:843-54.

[15] Pagano NJ. Exact solutions for composite laminates in cylindrical bending. J Comp Mater 1969;3:398-411.

[16] Murakami H. Laminated composite plate theory with improved inplane responses. J Appl Mech ASME 1986;53:661-6.

[17] Reddy JN. A generalisation of two-dimensional theories of laminated composite plates. Commun Appl Numer Methods 1987;3:173-80.

[18] Icardi U. Higher-order zig-zag model for analysis of thick composite beams with inclusion of transverse normal stress and sublaminates approximations. Compos Part B: Eng J 2001;32:343-54.

[19] Di Sciuva M, Icardi U. Numerical assessment of the core deformability effect on the behavior of sandwich beams. Compos Struct 2001:52:41-53.

[20] Averill RC, Yip YC. Development of simple, robust finite elements based on refined theories for thick laminated beams. Compos Struct 1996;59:529-46.

[21] Cho Y-B, Averill RC. An improved theory and finite element model for laminated composite and sandwich beams using first-order zig-zag sublaminate approximations. Compos Struct 1997;37(3-4): 281-98.

[22] Carrera E. On the use of the Murakami's zig-zag function in the modeling of layered plates and shells. Comput Struct 2004;82:541-54.

[23] Carrera E. Historical review of zig-zag theories for multilayered plates and shells. Appl Mech Rev 2003;56(3):287-308.
[24] Noor AK, Burton WS. Assessment of computational models for multilayered composite shells. Appl Mech Rev 1990;43(4):67-97.

[25] Reddy JN. Mechanics of laminated composite plates - theory and analysis. Boca Raton, FL: CRC Press; 1997.

[26] Carrera E. Theories and finite elements for multilayered, anisotropic, composite plates and shells. Arch Comput Methods Eng 2002;9: $87-140$.

[27] Touratier M. A generalization of shear deformation theories for axisymmetric multilayered shells. Int J Solids Struct 1992;29:1379-99.

[28] Ganapathi M, Patel BP, Polit O, Touratier M. A $c^{1}$ finite element including transverse shear and torsion warping for rectangular sandwich beams. Int J Numer Methods Eng 1999;45:47-75.

[29] Li X, Liu D. Generalized laminate theories based on double superposition hypothesis. Int J Numer Methods Eng 1997;40: $1197-212$.

[30] Ali JSM, Bhaskar K, Varadan TK. A new theory for accurate thermal/mechanical flexural analysis of symmetric laminated plates. Compos Struct 1999;45:227-32.

[31] Kapuria S, Dumir PC, Jain NK. Assessment of zigzag theory for static loading, buckling, free and forced response of composite and sandwich beams. Compos Struct 2004;64:317-27.

[32] Chaudhri RA. An equilibrium method for prediction of transverse shear stresses in a thick laminated plate. Comput Struct 1986;23 $139-46$.

[33] Barbero EJ, Reddy JN. An accurate determination of stresses in thick laminates using a generalized plate theory. Int J Numer Methods Eng 1989;28:2275-92.

[34] Tahani M. Analysis of laminated composite beams using layerwise displacement theories. Compos Struct 2007;79(4):535-47.

[35] Han J, Hoa SV. A three-dimensional multilayer composite finite element for stress analysis of composite laminates. Int $\mathbf{J}$ Numer Methods Eng 1993;36:3903-14.

[36] Touratier M. An efficient standard plate theory. Int J Eng Sci 1991;29:901-16

[37] Touratier M. A refined theory of laminated shallow shells. Int J Solids Struct 1992;29(11):1401-15

[38] Vidal P, Polit O. A thermomechanical finite element for the analysis of rectangular laminated beams. Finite Elements Anal Des 2006;42(10):868-83.

[39] Sze KY, Chen R, Cheung YK. Finite element model with continuous transverse shear stress for composite laminates in cylindrical bending. Finite Elements Anal Des 1998;31:153-64.

[40] Wu Z, Chen R, Chen W. Refined laminated composite plate element based on global-local higher-order shear deformation theory. Compos Struct 2005;70(2):135-52.

[41] Polit O, Touratier M, Lory P. A new eight-node quadrilateral shearbending plate finite element. Int J Numer Methods Eng 1994;37: 387-411.

[42] Pagano NJ. Exact solutions for rectangular bidirectional composites and sandwich plates. J Comp Mater 1970;4:20-34

[43] Hu H, Belouettar S, Daya EM, Potier-Ferry M. Evaluation des divers modèles analytiques pour les structures sandwich viscoélastiques. In: Proceeding du VII ${ }^{\mathrm{e}}$ me colloque en Calculs de Structures, Giens, France, 2005, p. 181-8 [in french].

[44] Karama M, Afaq KS, Mistou S. Mechanical behaviour of laminated composite beam by the new multi-layered laminated composite structures model with transverse shear stress continuity. Int J Solids Struct 2003;40:1525-46.

[45] Karama M, Abou Harb B, Mistou S, Caperaa S. Bending, buckling and free vibration of laminated composite with a transverse shear stress continuity model. Comp Part B: Eng J 1998;29:223-34.

[46] Ansys. Ansys theoretical manual. Swanson Analysis Inc, 1986. 